Article

\title{
Effect of Disk Laser Beam Offset on the Microstructure and Mechanical Properties of Copper-AISI 304 Stainless Steel Dissimilar Metals Joints
}

\author{
Miroslav Sahul ${ }^{1, *}$, Ema Tomčíková ${ }^{1}$, Martin Sahul ${ }^{2}$, Matej Pašák ${ }^{2}$, Barbora Ludrovcová $^{1}$ and \\ Erika Hodúlová $^{1}$ \\ 1 Department of Welding and Joining of Materials, Institute of Production Technologies, Faculty of Materials \\ Science and Technology in Trnava, Slovak University of Technology in Bratislava, J. Bottu 25, 91724 Trnava, \\ Slovakia; ema.tomcikova@stuba.sk (E.T.); barbora.ludrovcova@stuba.sk (B.L.); \\ erika.hodulova@stuba.sk (E.H.) \\ 2 Institute of Materials Science, Faculty of Materials Science and Technology in Trnava, Slovak University of \\ Technology in Bratislava, J. Bottu 25, 91724 Trnava, Slovakia; martin.sahul@stuba.sk (M.S.); \\ matej.pasak@stuba.sk (M.P.) \\ * Correspondence: miroslav.sahul@stuba.sk; Tel.: +421-910-135-972
}

Received: 26 August 2020; Accepted: 23 September 2020; Published: 27 September 2020

\begin{abstract}
Deoxidized oxygen free copper C12200, $1 \mathrm{~mm}$ in thickness, was welded to 1-mm thick AISI 304 stainless steel with disk laser. The butt-welded joints were produced with different welding parameters. Full factorial design of experiment (DoE) approach consisting of three factors and two levels was utilized. Laser powers used for welding were 1.3 and $1.9 \mathrm{~kW}$ and welding speeds of 20 and $30 \mathrm{~mm} / \mathrm{s}$. Two beam offsets were tested, namely, $100 \mu \mathrm{m}$ toward copper side and $200 \mu \mathrm{m}$ toward AISI 304 steel. It was found that beam offset possesses the largest influence on the welded joints' tensile strength. Tensile strengths attained values more than 3.7 times higher in comparison to the AISI 304 steel beam offset. When lower laser power was used, the higher tensile strength was attained for copper sheet offset. Higher microhardness was observed when laser beam was offset to AISI 304 steel side. The average microhardness of the weld metal was higher than that of the weaker base material, copper sheet. Energy dispersive X-ray spectroscopy (EDS) analysis confirmed the heterogeneity in elemental composition across the welded joint interface, being lower when laser beam was offset to AISI 304 steel side. On the other hand, the copper content dropped to the average composition of weld metal at the distance of about $140 \mu \mathrm{m}$ from copper-weld metal interface.
\end{abstract}

Keywords: disk laser welding; oxygen-free copper; AISI 304 stainless steel; beam offset; design of experiment

\section{Introduction}

Welding of dissimilar materials is nowadays a great challenge due to differences of the properties of materials to be welded [1-3]. One such combination represents copper to stainless steel welded joints, which are extensively utilized in the nuclear, power generation, automotive, and chemical industries [4,5]. There is a large mismatch in the thermophysical properties of the mentioned metals [6]. Copper is characterized by high thermal conductivity in comparison to AISI 304 stainless steel. Usually, it is necessary to preheat the copper in order to obtain full penetration across material thickness. Furthermore, the difference between melting points of selected materials are also distinct [7]. Because of the lower melting point of copper, the formation of liquation cracking in the heat affected zone (HAZ) 
of stainless steel could be observed. This issue results from the penetration of copper liquid into the grains of HAZ and followed by reduction of the cohesion strength of stainless steel (SS) grains [8]. Laser beam welding is a promising technology to eliminate the mentioned issue. Because of lower heat input, the width of HAZ is expected to be minimal, resulting also in a narrower region of copper that underwent recrystallization [9]. Cheng et al. [6] studied the application of various filler materials for joining such combination of metals. They observed that maximum tensile strength of $80 \%$ of that of copper base material was attained when $\mathrm{Cu}$-based filler material was used. The authors found that the fracture was observed in the heat-affected zone of copper due to grain coarsening and reduction of dislocation density resulting from annealing of the zone [6]. Similarly, various filler materials were studied also by Shiri et al. [10]. They found that welded joints without weld defects could be produced with $\mathrm{Cu}$-based filler material. Tensile strength of the welded joint reached $96 \%$ of the tensile strength of copper [10]. The laser welded joints between copper alloy C21000 and AISI 304 stainless steel investigated by [11] exhibited the strength of $85 \%$ of the copper strength. The highest hardness was observed at the weld metal-stainless steel interface. The welded joints failed at the $\mathrm{Cu}$-weld metal interface. In another study, local properties of gas tungsten arc welding (GTAW) of C21000 copper alloy to AISI 304 stainless steel welded joints produced with ERNiCu-7 filler material were investigated [12]. Meng et al. [13] conducted laser-arc hybrid welding and observed that, at the laser beam offset ranging from 0.5 to $1.0 \mathrm{~mm}$ toward $\mathrm{Cu}$ sheet, the weld metal consisted of a Cu-rich matrix with dispersion of Fe-based particles. Contrarily, Chen et al. [14] utilized laser beam offsetting to the stainless-steel sheet side. The tensile strength was dependent on the amount of melted copper. The maximum tensile strength reached $260 \mathrm{MPa}$. Fracture during tensile testing of welds occurred at the weld metal-copper interface, the HAZ of copper and weld metal [14]. Mannucci et al. [15] observed in weld metal various microstructures based on $\mathrm{Cu}$ content, namely, solid solution with the content of $\mathrm{Cu} \geq 2$ at. \%, Cu-rich droplets with higher than 20 at. \% of copper, and $\mathrm{Cu}$-enriched zones between austenite cells ( 2 to 5 at. \% Cu). Kar et al. [16] investigated the influence of beam oscillation on $\mathrm{Cu}$-AISI 304 joints produced by electron beam welding and found that oscillation with optimum diameter resulted in an increase in impact strength and elongation in comparison to welds made without oscillation of electron beam. Contrarily, tensile strength of welds was similar to that produced without oscillation [16]. Zhang et al. [17] utilized electron beam welding QCr0.8 copper alloy to AISI 304 stainless steel with copper filler wire. The authors observed that the weakest region of the welded joint was the melted zone at the weld metal-copper side interface. Grain coarsening was observed in the mentioned zone [17]. Kuryntsev et al. [18] performed fiber laser welding with de-focused beam in conduction mode, and beam offset to stainless steel side was realized. The authors found that the width of layer between stainless steel and copper ranged from 41 to $53 \mu \mathrm{m}$. The microhardness measured in this location ranged from 128 to 170 HV0.01 [18]. Guo et al. [19] evaluated the effect of beam offset during electron beam welding of copper to stainless steel. The microstructure of weld consisted of $\varepsilon$-phase dendrites and a small portion of $\gamma$-phase dendrites in the case of beam offsets toward copper side. Offset to stainless steel side resulted in the $\gamma$-dendrites' formation with a small fraction of $\varepsilon$-phase [19]. Zhang et al. [20] studied the mechanism of the formation of welds between Ti alloy and stainless steel with the use of copper interlayer. They observed that at the interface between copper and stainless steel the weld was formed by dilution of copper and intermixing with stainless steel [20]. Similarly, the interfaces between copper filler material and AISI 304 stainless steel were studied within produced brazed joint by [21] and welded joint by [22]. Research has also focused on the welding of the mentioned combination of materials with explosive bonding [23,24]. In this study, we used DoE when disk laser welding copper to AISI 304 stainless steel with the goal of determining the most significant welding parameter from the microstructure, chemical composition, microhardness, and tensile strength point of view. Two beam offsets were tested, including offsets to the copper side and stainless-steel sheet side. A linear model for tensile strength based on laser power, welding speed, and beam offset was developed. 


\section{Materials and Methods}

C12200 deoxidized oxygen-free copper with content of phosphorus and AISI 304 austenitic stainless steel with dimensions of $50 \times 100 \times 1 \mathrm{~mm}$ were used as base materials. Chemical composition of base materials is given in Tables 1 and 2. Optical emission spectrometer Bruker Q4 TASMAN (Bruker, Madison, WI, USA) was used for the measurements of chemical composition of base materials. Chemical composition was measured in three locations and the average value was calculated. Mechanical properties of base materials are given in Tables 3 and 4 . Weld surfaces were milled to achieve perfect contact of surfaces and cleaned with acetone. Butt joints were fabricated by solid state disk laser TruDisk 4002 (TRUMPF, Ditzingen, Germany). Based on preliminary tests in which 20 welded joints were produced, eight parameters' setup was chosen for DoE calculations. In preliminary tests, laser powers ranged from 0.7 to $1.9 \mathrm{~kW}$, welding speed was set to $30 \mathrm{~mm} / \mathrm{s}$, and beam offsets 100,200 , and $300 \mu \mathrm{m}$ toward AISI 304 steel and the same offsets toward copper were utilized. Furthermore, initial welds were produced without beam offsetting. Three factors, i.e., laser power, welding speed, and beam offset, were evaluated. Because of a very narrow weldability window, each factor was set to two levels. Thus, DoE of $2^{3}$ type, full factorial was chosen. Influence of beam offset on tensile strength was assessed. Laser light cable with the diameter of $200 \mu \mathrm{m}$ was used. The spot size was $200 \mu \mathrm{m}$. Laser beam was focused on the top surface of the materials to be welded. Positive beam offset was set to the AISI 304 steel side and negative beam offset was to copper side (Figure 1).

Table 1. Chemical composition of AISI 304 stainless steel (in wt. \%).

\begin{tabular}{ccccccccccc}
\hline $\mathbf{C r}$ & $\mathbf{N i}$ & $\mathbf{M n}$ & $\mathbf{S i}$ & $\mathbf{M o}$ & $\mathbf{C}$ & $\mathbf{P}$ & $\mathbf{S}$ & $\mathbf{A l}$ & $\mathbf{C u}$ & $\mathbf{F e}$ \\
\hline 16.55 & 9.37 & 1.55 & 1.91 & 0.17 & 0.09 & 0.084 & 0.044 & 0.39 & 1.08 & Balance \\
\hline
\end{tabular}

Table 2. Chemical composition of copper (in wt. \%).

\begin{tabular}{cccccc}
\hline $\mathbf{C u}$ & $\mathbf{M n}$ & $\mathbf{F e}$ & $\mathbf{P}$ & $\mathbf{S i}$ & Al \\
\hline Balance & 0.02 & 0.024 & 0.0075 & 0.108 & 0.02 \\
\hline
\end{tabular}

Table 3. Mechanical properties of C12200 copper.

\begin{tabular}{ccc}
\hline Tensile Strength Rm (MPa) & Yield Strength Rp0.2 (MPa) & Ductility (\%) \\
\hline 298 & 252 & 15 \\
\hline
\end{tabular}

Table 4. Mechanical properties of AISI 304 stainless steel.

\begin{tabular}{ccc}
\hline Tensile Strength Rm (MPa) & Yield Strength Rp0.2 (MPa) & Ductility (\%) \\
\hline 794 & 404 & 34 \\
\hline
\end{tabular}



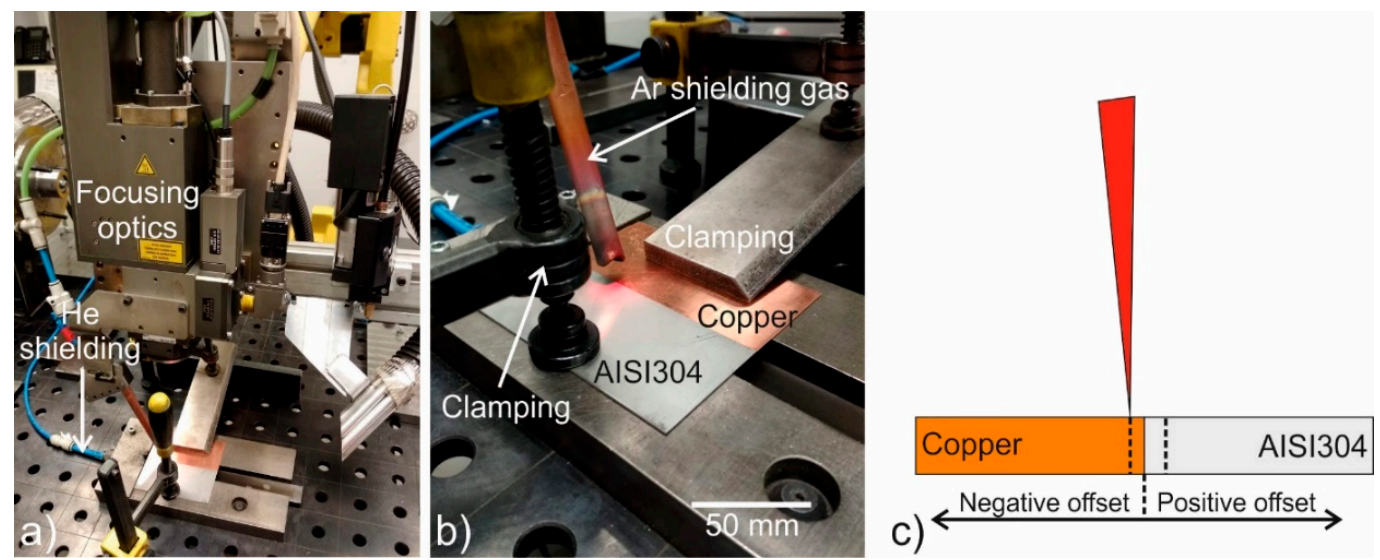

Figure 1. (a) Disk laser welding workplace; (b) setup to welded materials; (c) schematic overview of beam offset application.

Argon 4.6 shielding was utilized for weld bead protection. Shielding gas flow rate was $18 \mathrm{~L} / \mathrm{min}$. Root shielding was ensured by He shielding with flow rate of $16 \mathrm{~L} / \mathrm{min}$. Welding parameters used for DoE trials along with calculated heat inputs are given in Table 5. DoE was carried out in Minitab 17.3.1 (Minitab, Ltd., Coventry, UK) statistical software. Heat input in disk laser welding was calculated according to the following equation [25]:

$$
Q=\frac{P}{v}(\mathrm{~J} / \mathrm{mm})
$$

where $P$ is laser power in $\mathrm{W}$ and $v$ equals to the welding speed in $\mathrm{mm} / \mathrm{s}$.

Table 5. Welding parameters used for DoE.

\begin{tabular}{ccccc}
\hline Welded Joint No. & Laser Power $\mathbf{( k W )}$ & Welding Speed $\mathbf{( m m} / \mathbf{s})$ & Beam Offset $(\boldsymbol{\mu m})$ & Heat Input $(\mathbf{J} / \mathbf{m m})$ \\
\hline 1 & 1.9 & 20 & +200 & 95 \\
2 & 1.3 & 30 & +200 & 43.3 \\
3 & 1.3 & 20 & +200 & 65 \\
4 & 1.3 & 30 & -100 & 43.3 \\
5 & 1.9 & 20 & -100 & 95 \\
6 & 1.9 & 30 & +200 & 63.3 \\
7 & 1.9 & 30 & -100 & 63.3 \\
8 & 1.3 & 20 & -100 & 65 \\
\hline
\end{tabular}

The cross-sections and local microstructures of welded joints were documented by ZEISS LSM 700 laser scanning confocal microscope (Carl Zeiss Microscopy GmbH, Jena, Germany). Electrolytic etching in $10 \%$ oxalic acid solution was used to reveal microstructure of stainless steel and stainless steel-rich weld metal. Solution of $20 \mathrm{~mL}$ nitric acid and $20 \mathrm{~mL}$ distilled water was used for etching copper and copper-rich weld metal. JEOL JSM 7600 F scanning electron microscope with EDS detector (JEOL Ltd., Tokyo, Japan) was applied for the study of chemical composition in selected welded joints. EDS analysis was carried out on etched samples. Microhardness course across dissimilar metal-welded joints was measured by Buehler IndentaMet 1100 Series tester (Buehler, Lake Bluff, IL, USA) with the loading of $0.98 \mathrm{~N}$. Distance between indents was $100 \mu \mathrm{m}$. Totally, five rows of indents were constructed during measurements of microhardness map for sample No. 5. Distance between rows was set to $200 \mu \mathrm{m}$. One row in the middle of the thickness was measured for sample No. 1. Dwell time was $10 \mathrm{~s}$. Tensile strength test was carried out on LabTest 5.250 SP1-VM tensile testing machine (LABORTECH s.r.o., Opava, Czech Republic). The crosshead speed was $3 \mathrm{~mm} / \mathrm{s}$. 


\section{Results and Discussion}

\subsection{Weld Bead and Root Appearance}

Weld bead and weld root appearance for dissimilar welded joint No. 2 are given in Figure 2a,b. The width of the weld bead was $1.034 \mathrm{~mm}$ (Table 4). The surface of the weld bead was smooth. Lack of fusion on the copper side of root was observed due to low heat input. The surface of the weld bead No. 3 (Figure 2c) showed no defects. The mentioned welded joint was produced with a higher heat input of $65 \mathrm{~J} / \mathrm{mm}$. The welding speed decreased to $20 \mathrm{~mm} / \mathrm{s}$. The weld bead increased to $1.228 \mathrm{~mm}$. Lack of fusion from the copper root (Figure $2 \mathrm{~d}$ ) was observed again from the weld root side, as a result of insufficient heat input. Furthermore, it was evident that the beam offset of $200 \mu \mathrm{m}$ to AISI 304 steel was too large. In such cases, the temperatures sufficient to melt completely the copper are not high enough. Thus, the beam offset $100 \mu \mathrm{m}$ toward copper side (weld No. 4) was tested. The width of the weld was $1.097 \mathrm{~mm}$. Only the value of the beam offset was different in comparison to weld No. 2 . There was not evident difference in the weld metal size, confirming that the beam offset had a similar effect on the weld width. Variation of offset to the copper side (weld No. 4) provided more uniform heat distribution, even though the heat input was only $43.3 \mathrm{~J} / \mathrm{mm}$, as in sample No. 2 . In the case of weld No. 4, it was enough for formation of the uniform welded joint. Both the weld surface (Figure 2e) and the root (Figure 2f) exhibited a uniform and smooth surface. Welding speed decreased to $20 \mathrm{~mm} / \mathrm{s}$ to increase heat input to $65 \mathrm{~J} / \mathrm{mm}$, in the case of weld No. 8. Welded joint No. 8 possessed a smooth weld bead pattern (Figure 2g,h). Weld sagging was observed on the AISI 304 side. The weld bead width was $1.063 \mathrm{~mm}$. Measured widths for welded joints are summarized in Table 6.

Table 6. Measured width for dissimilar metal-welded joints.

\begin{tabular}{cc}
\hline Welded Joint No. & Weld Width $(\mathbf{m m})$ \\
\hline 1 & 1.969 \\
2 & 1.034 \\
3 & 1.228 \\
4 & 1.097 \\
5 & 1.249 \\
6 & 1.246 \\
7 & 0.89 \\
8 & 1.063 \\
\hline
\end{tabular}

In the next step, the laser power increased to $1.9 \mathrm{~kW}$ (weld No. 7). Since the beam offset was to the copper side, more copper was melted, resulting in higher intermixing of both metals (Figure 3a,b). This fact needs to be confirmed by EDS analysis. The measured weld bead width was $0.896 \mathrm{~mm}$. 


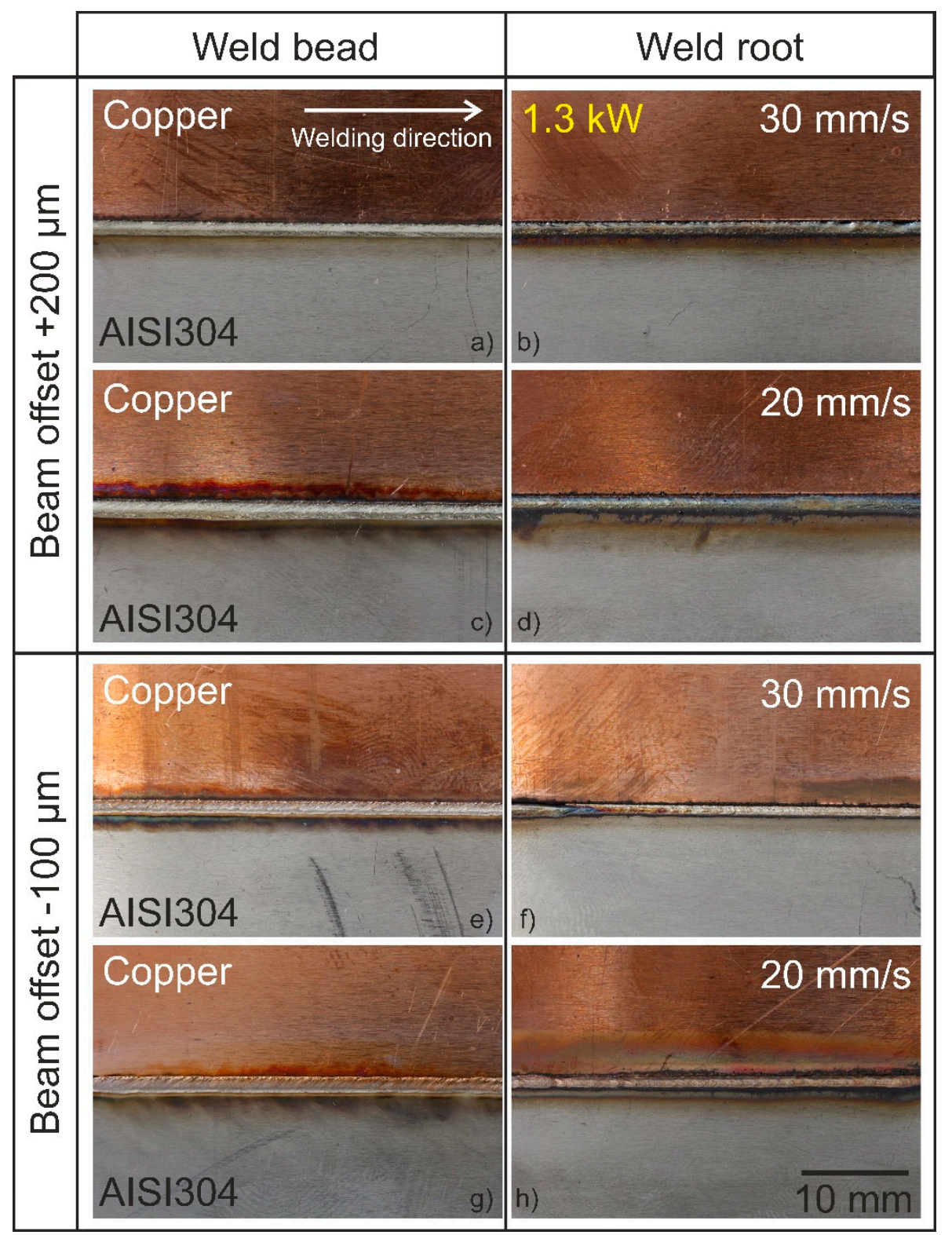

Figure 2. Weld bead and root appearance for joints produced with laser power of $1.3 \mathrm{~kW}$, (a) weld bead and (b) weld root of weld No. 2, (c) weld bead and (d) weld root of weld No. 3, (e) weld bead and (f) weld root of weld No. 4, (g) weld bead and (h) weld root of weld No. 8. 


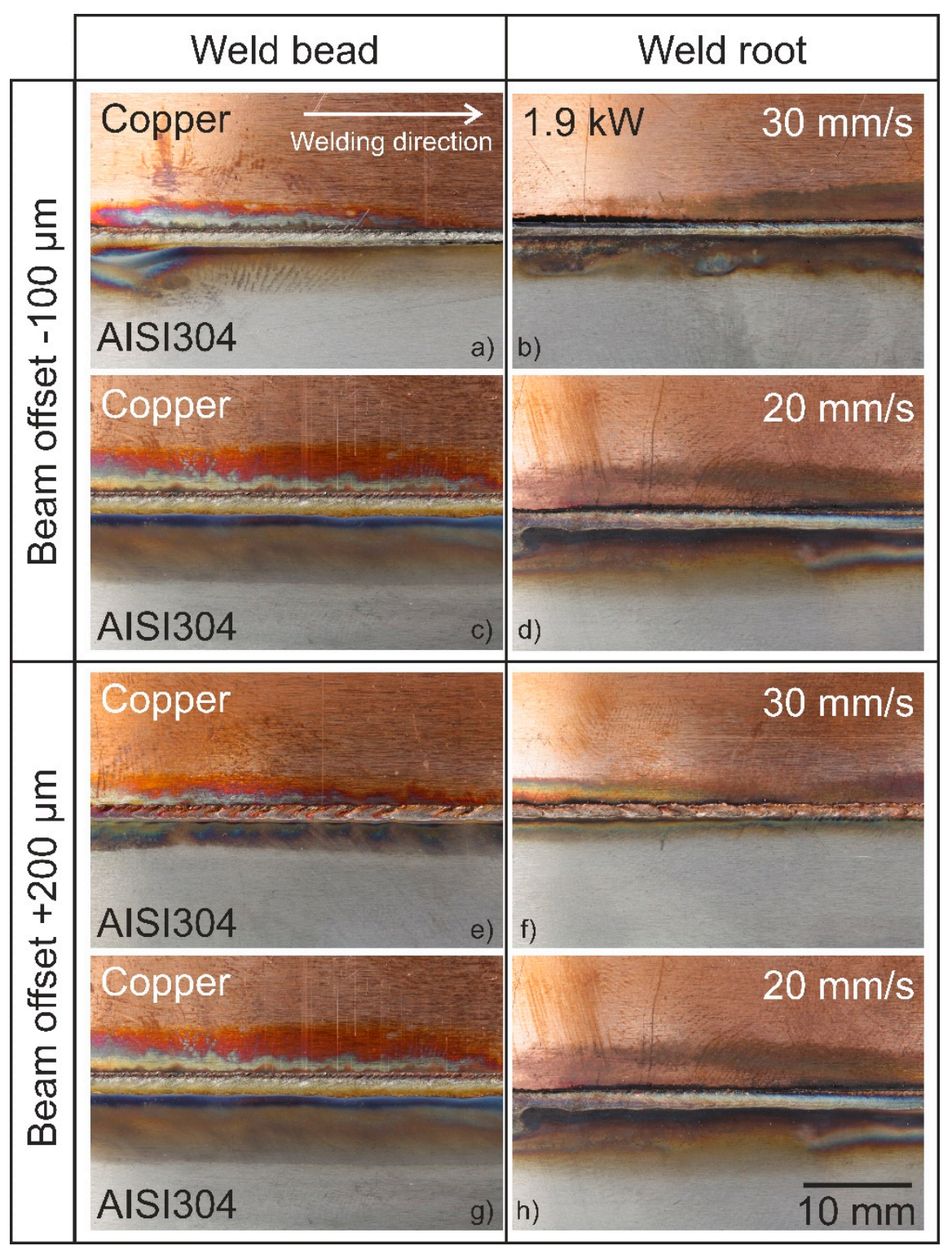

Figure 3. Weld bead and root appearance for welded joints produced with laser power of $1.9 \mathrm{~kW}$. (a) weld bead and (b) weld root of weld No. 7, (c) weld bead and (d) weld root of weld No. 5, (e) weld bead and (f) weld root of weld No. 6, (g) weld bead and (h) weld root of weld No. 1.

Welding speed decreased to $20 \mathrm{~mm} / \mathrm{s}$ in the case of weld No. 5 (Figure 3c). The heat input increased to $95 \mathrm{~J} / \mathrm{mm}$. Weld bead width was $1.249 \mathrm{~mm}$. The heat-affected zone width of copper increased as a result of the higher heat input used. Furthermore, high thermal conductivity of copper contributed to that fact. Discoloration on AISI 304 surface of the weld bead and root (Figure 3d) is a sign of insufficient shielding of the welded joint.

Further, the beam offset $200 \mu \mathrm{m}$ to AISI 304 steel was evaluated (weld No. 6). The heat input was $63.3 \mathrm{~J} / \mathrm{mm}$. The weld bead width was $1.246 \mathrm{~mm}$. Irregular surface appearance was observed (Figure 3e). Similarly, weld root appearance (Figure 3f) exhibited the same characteristic. It could be associated with the high reflectivity of laser radiation by copper surface, resulting in the instability of the keyhole during welding. Thus, the welding speed decreased to $20 \mathrm{~mm} / \mathrm{s}$. Weld surface and weld root No. 1 is shown in Figure 3g,h. The heat input increased to $95 \mathrm{~J} / \mathrm{mm}$. Similarly, weld bead width was raised to $1.969 \mathrm{~mm}$. An undercut was observed at the copper side. Slight discoloration could be observed on the AISI 304 top surface. The process was more stable resulting from higher heat input; thus, the irregularities of the weld appearance were eliminated. 


\subsection{Analysis of Weld Cross-Sections}

Cross-sections of selected welded joints are given in Figure 4. It is visible that the weld metal of all welded joints consists of two distinct zones, with the darker zone being closer to copper and the brighter one being closer to AISI 304 steel. Melted locations are characterized by asymmetric geometry due to large differences in thermal conductivities and laser absorptivity by surface of metals, as well [15].
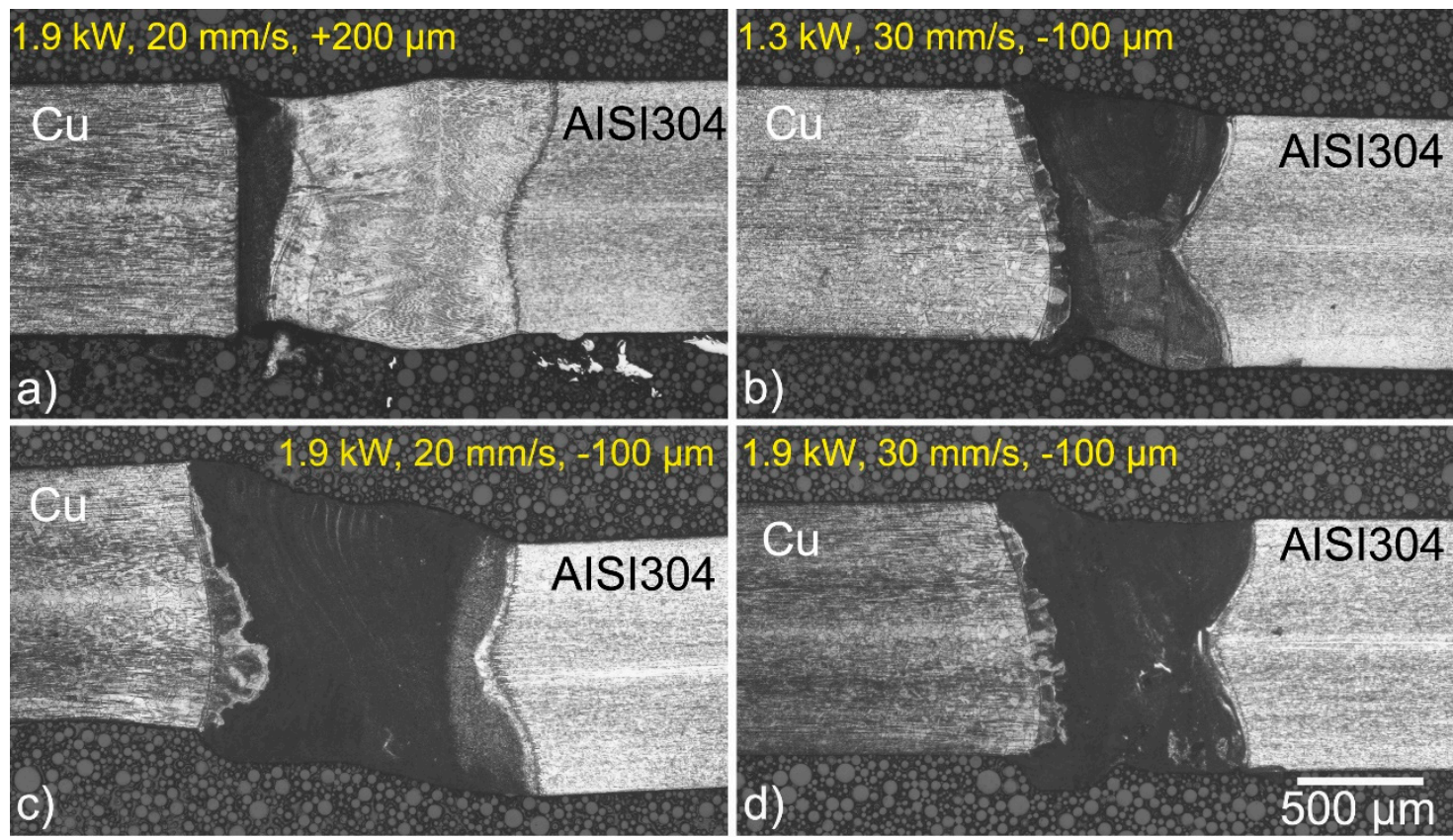

Figure 4. Cross-sections of dissimilar metals-welded joints produced with different welding parameters. (a) weld No. 1, (b) weld No. 4, (c) weld No. 5 and (d) weld No. 7.

Influence of laser beam offset on welded joint geometry is shown in Figure 4a,c. Welded joints were produced with the same welding speed and laser power.

Copper HAZ-weld metal interface of the weld No. 1 exhibited the characteristic of brazed joint. The joint was produced through so-called weld-brazing [26-28]. This is attributed to the larger beam offset to AISI 304 side. It resulted in melting of AISI 304 material followed by wetting of copper interface. High thermal conductivity of copper contributed to the weld-brazing effect. Contrarily, a typical welded joint interface could be seen on the steel side. Fusion zone of sample No. 5, where beam offset towards copper sheet was utilized, showed intermixing of both welded metals. Based on the cross-section, it was evident that beam offset had significant influence on welded joint geometry. Slight displacement of the welded materials on both samples can be seen.

Difference of laser power and, thus, heat input on bead geometry can be seen on samples No. 4 (Figure 4b) and No. 7 (Figure 4d). Higher heat input used for production of weld No. 7 resulted in a larger fusion zone.

Different welding speeds were used for production of weld No 5. and No. 7. Welding speed for sample No. 5 (Figure 4c) was $20 \mathrm{~mm} / \mathrm{s}$ and for No. 7 (Figure 4d) it was $30 \mathrm{~mm} / \mathrm{s}$. Geometry of the fusion zone was similar in both cases. Sheets' misalignment was observed in weld No. 5. Higher heat input of $95 \mathrm{~J} / \mathrm{mm}$ resulted in the wider fusion zone. Fuzion zone of copper was observed at the copper side. Increase in welding speed to $30 \mathrm{~mm} / \mathrm{s}$ was used in the case of sample No. 7. Lower heat input of $63.3 \mathrm{~J} / \mathrm{mm}$ used for production of weld No. 7 resulted in the narrowing of the weld metal. Nguyen et al. [29] observed that an increase in welding speed resulted in the reduction of porosity and cracking. 


\subsection{Analysis of the Microstructure}

Copper base metal-HAZ-fusion zone transition of weld No. 1 is documented in Figure 5a. The microstructure of copper base metal is characterized by texture, i.e., the grains are elongated in the direction of rolling. Copper exhibited in the middle of its thickness the characteristic of recrystallization. On the right-middle side is the heat-affected zone and on the far right is the fusion zone. Grain size in the HAZ increased due to the higher temperatures near the fusion zone. Only stainless steel is melted by laser heating, which means welding for the stainless steel. Contrarily, copper did not melt. Only the small zone at the former upper edge of copper melted. For weld-brazing mode, there was a characteristic planar interface between copper and weld metal. The material of molten pool was wetting the copper side.
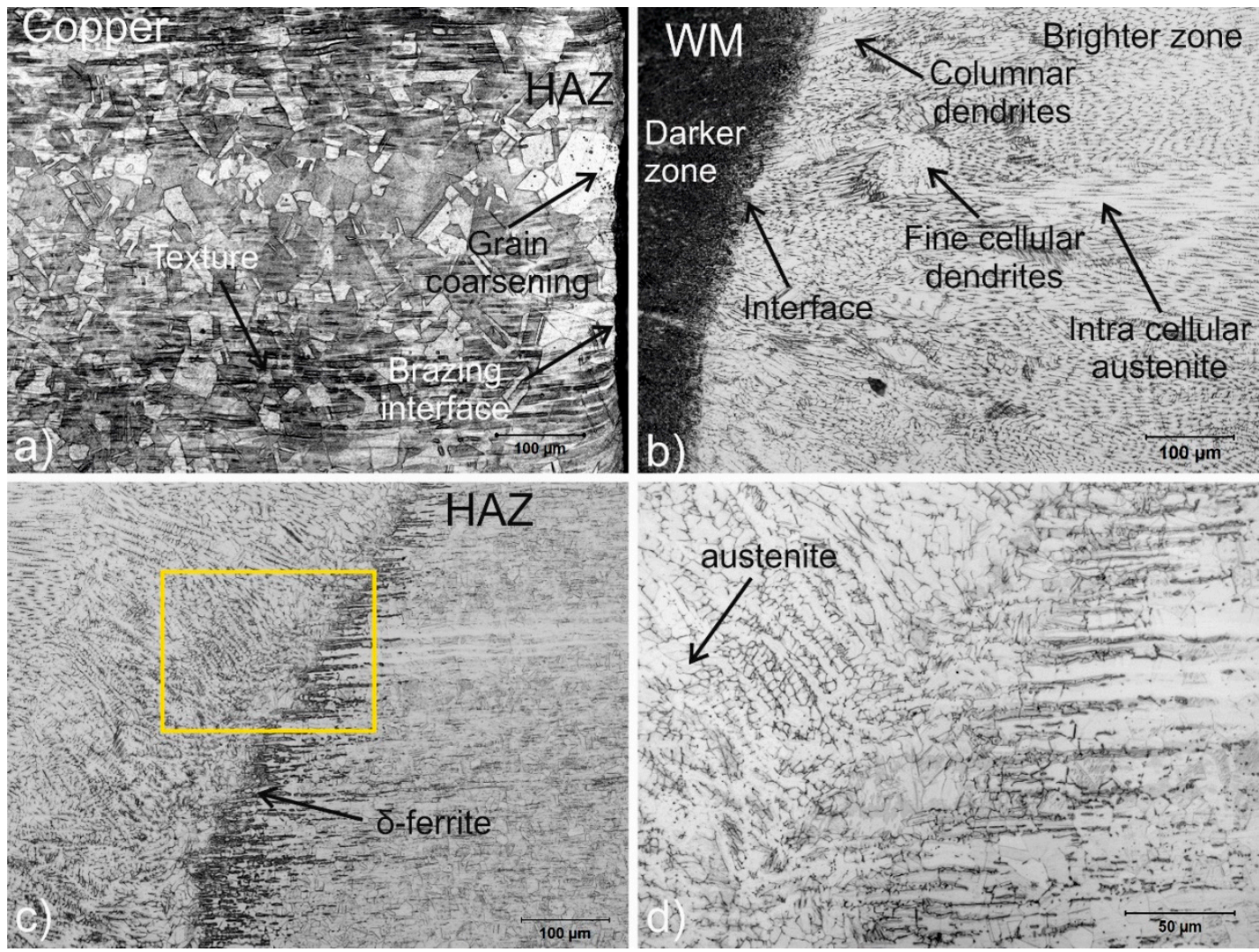

Figure 5. (a) Copper base metal-HAZ-fusion zone transition of weld No. 1; (b) copper weld metal-AISI 304 weld metal interface; (c) weld metal-AISI 304 HAZ interface; (d) higher magnification of the zone marked in (c).

The microstructure of the weld metal exhibited a dendritic characteristic. The weld metal consisted of two parts, a darker one and a brighter one. The brighter zone was formed by austenite dendrites. Interdendrite spacings were characterized by the presence of $\delta$-ferrite. Columnar dendrites were observed at the interface between the darker and brighter zones (Figure 5b). Furthermore, fine cellular dendrites were documented. The weld metal-HAZ of the stainless-steel side is shown in Figure 5c. The $\delta$-ferrite was observed at the interface. Columnar dendrites grew perpendicularly to the fusion line. Higher magnification of the mentioned zone is given in Figure $5 \mathrm{~d}$.

Weld bead width of the sample No. 5 was $1.249 \mathrm{~mm}$. The offset to copper side resulted in intermixing of both materials. It is noticeable that in the Figure $6 \mathrm{a}$ the weld does not exhibit any planar interface along the copper side, which confirms that both materials were metallurgically joined. Contrary to the previous welded joint, the copper was melted. Fine copper dendrites were observed at the interface (Figure 6b,d). The weld metal-AISI 304 interface was characterized by the same features 
as welded joint No. 5 . The $\Delta$-ferrite was detected at the interface (Figure 6c). A similar microstructure was observed by Mannucci et al. [15]. Their investigation was conducted with ytterbium doped yttrium aluminum garnet ( $\mathrm{Yb}: \mathrm{YAG}$ ) laser. Contrary to our findings, the authors observed some hot cracking [15].
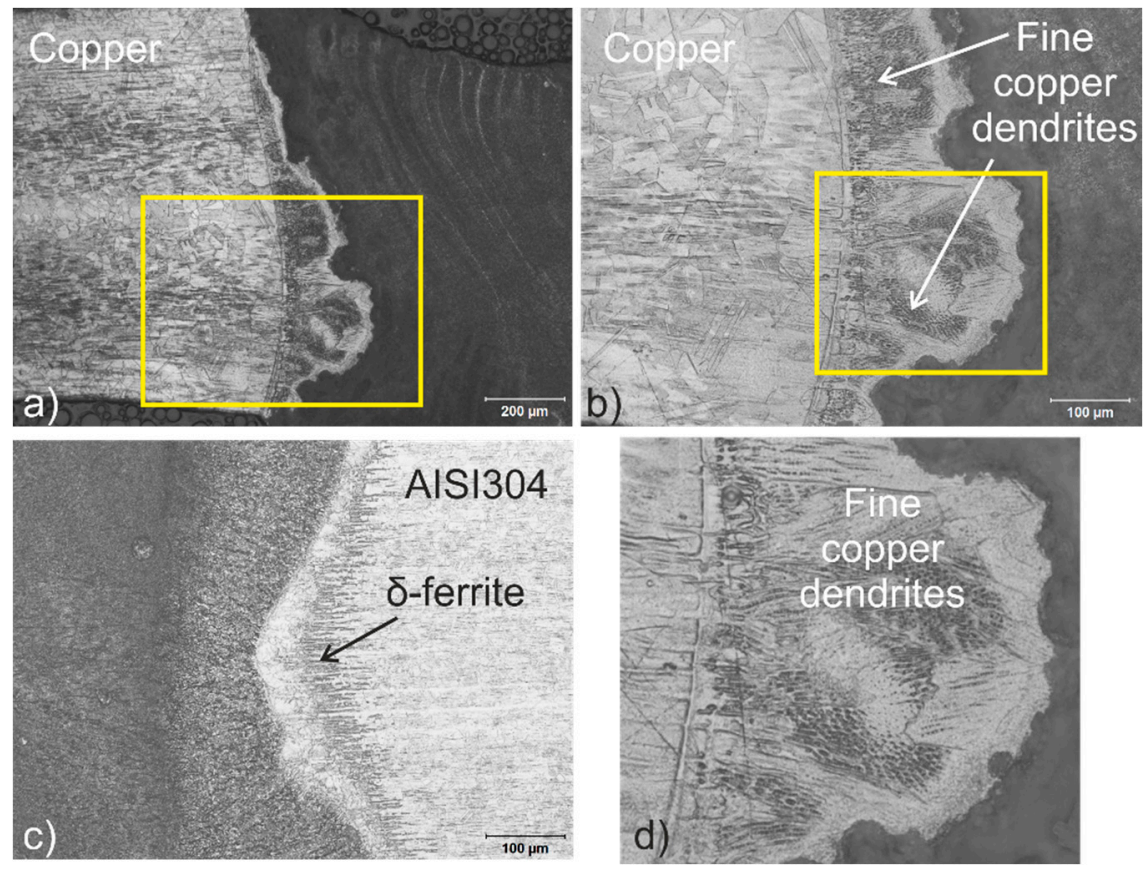

Figure 6. (a) Copper-HAZ-weld metal transition of weld No. 5; (b) higher magnification of copper-weld metal interface; (c) weld metal-AISI 304 HAZ interface, (d) fine copper dendrites zone at higher magnification.

\subsection{EDS Analysis}

EDS analysis was carried out in selected sites in weld metal for welded joint No. 5, in which beam offset to copper sheet was tested. The highest amount of copper was measured in Spectrum 4 (Figure 7). In direction to weld metal, at first, a dark zone was observed. In Spectra 2 and 6, a slightly lower amount of copper was detected. The content of element dropped to about half, i.e., about 48 at. \%. In those sites, a higher amount of iron was detected. Also, $\mathrm{Cr}$ content increase was noticed. Spectra 1,2, and 5 were specified by a higher amount of iron. In the white island, the composition was characterized by elemental intermixing. Iron content was 57 at. \% in this zone. Furthermore, 21 at. $\%$ of copper and 16 at. \% of chromium was detected. The bright sites toward the weld center were specific for their higher content of iron. The highest content was detected in Spectrum 3. This location belonged to the iron-rich side of the weld metal. 


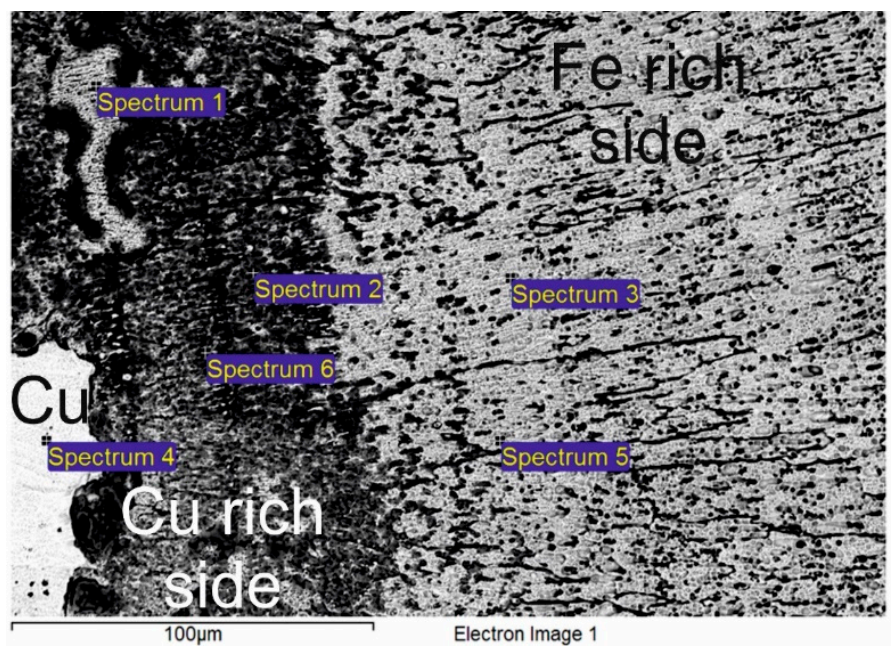

Figure 7. Locations of measurement of local chemical composition by means of EDS analysis (weld No. 5).

Chromium increased to 18 at. \% and copper dropped to 12 at. \%. Spectrum 5 contained 58 at. \% of iron and a slightly lower content of chromium in comparison to Spectrum 3. Furthermore, copper was slightly higher than for Spectrum 3. Due to beam offsetting to copper side, intermixing of both metals occurred. Results of EDS point analysis in local sites of weld metal are given in Table 7.

Table 7. EDS point analysis in local sites of weld metal (in at. \%).

\begin{tabular}{cccccc}
\hline Spectrum & $\mathbf{C r}$ & $\mathbf{M n}$ & $\mathbf{F e}$ & $\mathbf{N i}$ & $\mathbf{C u}$ \\
\hline 1 & 16.06 & 1.06 & 56.53 & 5.31 & 21.03 \\
2 & 10.74 & 1.10 & 35.60 & 3.73 & 48.84 \\
3 & 18.13 & 0.92 & 63.39 & 5.84 & 11.71 \\
4 & 0.63 & 0.16 & 3.05 & 0.42 & 95.74 \\
5 & 16.72 & 1.00 & 57.62 & 6.96 & 17.69 \\
6 & 11.38 & 1.19 & 36.07 & 3.67 & 47.70 \\
\hline
\end{tabular}

Variation in the chemical composition across the weld cross-section for sample No.1 and sample No. 5 was observed. EDS measurements were carried out along the cross-section to determine the change of selected elements.

A line scan of elemental distribution across the fusion zone for the weld-brazing mode in sample No. 1 is shown in Figure 8a. Although very low solid solubility in copper-iron binary diagram and short thermal cycle during laser welding existed, $\mathrm{Fe}, \mathrm{Cr}$, and Ni diffused to the copper sheet, but also copper diffused to the weld metal [30]. A decrease in copper toward weld metal (WM) was observed. Contrarily, an increase of $\mathrm{Fe}, \mathrm{Cr}$, and $\mathrm{Ni}$ in the direction to the $\mathrm{WM}$ was recorded. Fusion was confirmed by the presence of pores (Figure 8a).

Line scans of the main alloying elements across the copper-fusion zone-AISI 304 interface of sample No. 5 are given in Figure 8b. A decrease of copper in the direction from base material (BM) to weld metal (WM) was observed. Conversely, an increase in the content of $\mathrm{Fe}, \mathrm{Cr}$, and $\mathrm{Ni}$ was documented. Greater heterogeneity was observed in comparison with sample No. 1. At the distance of approximately $130 \mu \mathrm{m}$, a decrease in $\mathrm{Cu}$ content was observed. It proved that copper penetrated to the larger distance from the interface due to the concentration of laser beam energy to the coper side. The distribution of investigated elements varied significantly across the entire cross-section of the dissimilar metal-welded joint, thus confirming heterogeneous composition of the weld metal. Noticeable fluctuation of the elemental composition distribution was observed. 

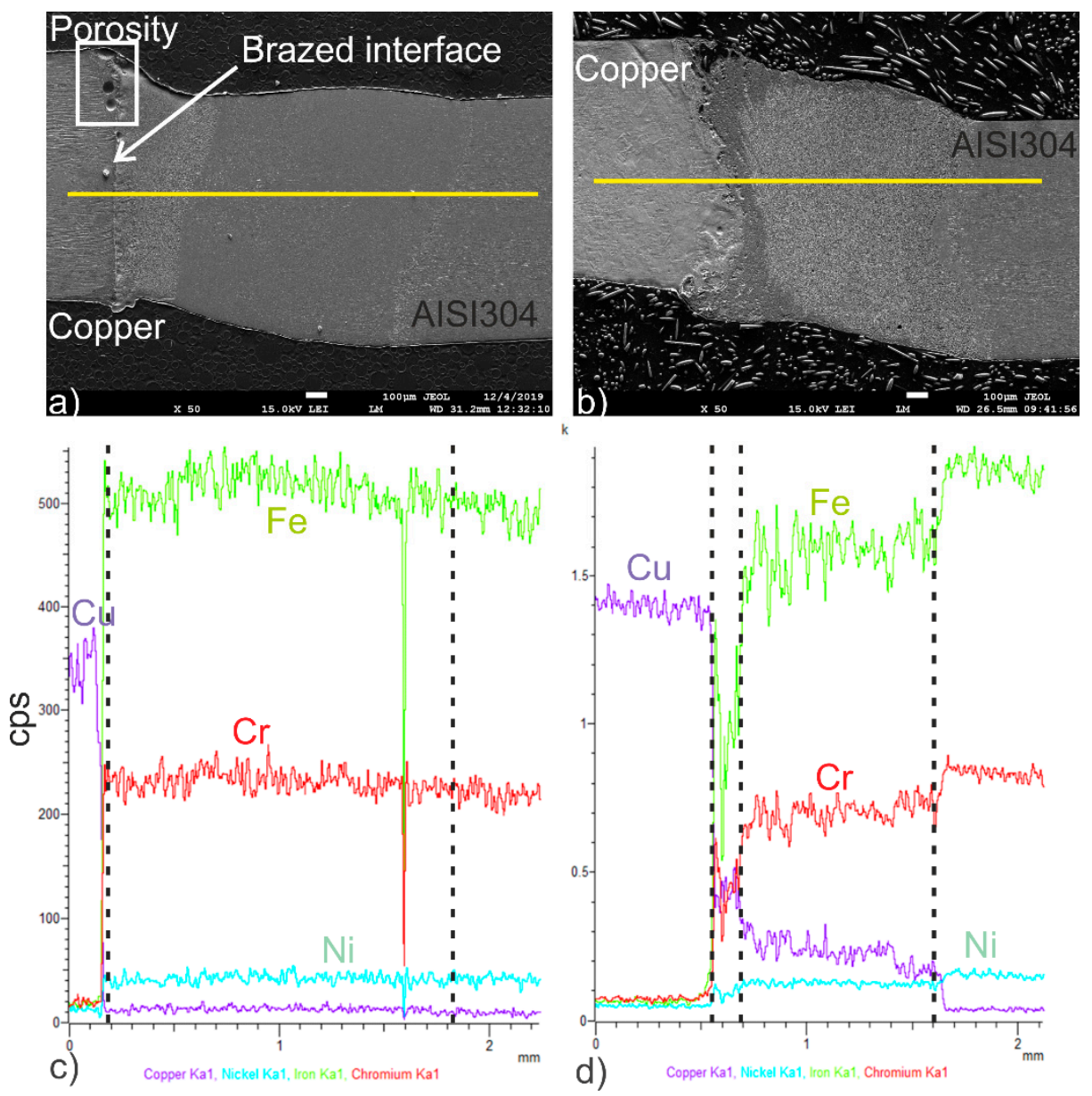

Figure 8. SEM image of area for EDS line analysis of the weld (a) No. 1 and (b) No. 5, elemental distribution across welded joint (c) No. 1 and (d) No. 5.

For closer inspection of intermixing of welded materials in the fusion zone, elemental mapping of $\mathrm{Cu}, \mathrm{Fe}, \mathrm{Cr}$, and $\mathrm{Ni}$ with better approximation was constructed (Figure 9). Visible intermixing of elements can be seen at the copper-fusion zone interface. Darker zones are expected to be originated from AISI 304 and brighter ones from the copper base material.

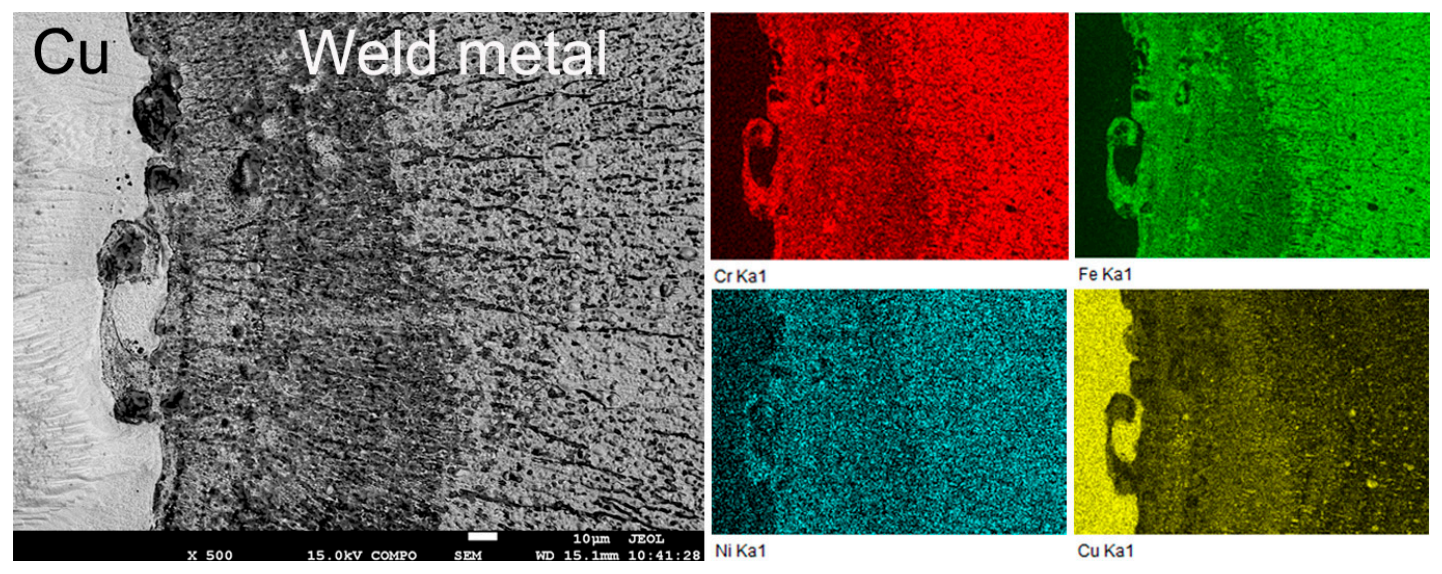

Figure 9. Elemental mapping across copper-weld metal interface (weld No. 5). 


\subsection{Microhardness Measurements}

The distribution of microhardness across dissimilar metal-welded joint No. 1 is given in Figure 10. It is evident that an increase of microhardness from copper side to fusion zone was recorded. Contrarily, the drop of microhardness from AISI 304 stainless steel toward the fusion zone was attained. The average microhardness of copper is $65 \mathrm{HV} 0.1$. The average microhardness of austenitic stainless steel is approximately $215 \mathrm{HV0.1}$. The mean microhardness of weld metal equals to $179 \mathrm{HV} 0.1$. The course of microhardness proved the heterogeneity of the produced weld metal. As it arose from the course of microhardness, the hardness of the fusion zone was greater than the hardness of the weaker base material, i.e., copper. Kar et al. [16] observed during investigation of the effect of beam oscillation on the properties of dissimilar welds higher hardness of electron beam welds in comparison to copper. The nature of the hardness variation of weld metal was based on the amount of intermixing of copper in the weld metal [16]. In the work of Weigl and Schmidt [31], the highest value of an average hardness in the weld zone was documented with a lateral beam displacement of $100 \mu \mathrm{m}$ into the stainless steel. The authors stated that this is associated to the amount of mixed copper and stainless steel [31].

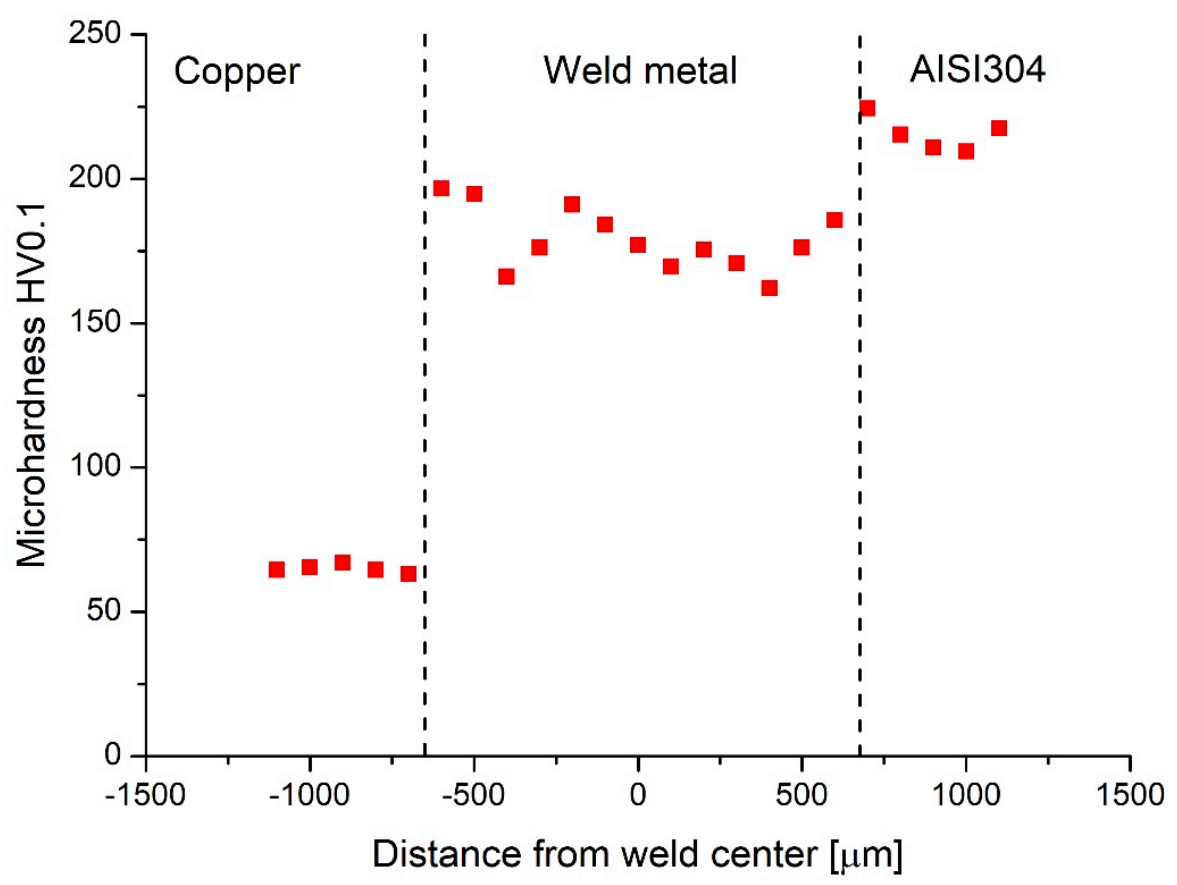

Figure 10. The distribution of microhardness across copper-weld metal-AISI 304 stainless steel interface (weld No. 1).

Figure 11 shows the microhardness map for dissimilar metals-welded joint No. 5. This sample was welded with the same laser power and welding speed as the previous sample, but the beam offset was changed $100 \mu \mathrm{m}$ to the copper side in this case. Microhardness contour plot derived from the microhardness measurements across the weld cross-section revealed that both base metals AISI 304 and copper had more uniform hardness distributions equivalent to their theoretically expected microhardness values. Additionally, the AISI 304 base metal and its heat-affected zone had similar microhardness due to the small heat input in laser welding, significantly eliminating the grain growth close to the weld metal. Although the heat input in laser welding was low, the drop of microhardness in copper HAZ was recorded. It was associated with the high thermal conductivity of copper, allowing the heat to spread to longer distance from the heat source. When taking into account that copper was as-rolled, the heating after deformation resulted in recrystallization [32] or grain growth (Figure 6a). It depended on deformation and the amount of heat. Dislocation density decreased and microhardness dropped as a result [6]. The mean microhardness dropped in the weld metal to the value of 140 HV0.1 in comparison to weld No. 1. This was associated to the higher intermixing with copper, resulting 
in lowering the mean microhardness. The highest microhardness in Metal Inert Gas-Tungsten Inert Gas (MIG-TIG) both side arc welds was observed by Cheng et al. [6] in AISI 304 base material and was approximately $200 \mathrm{HV}$. The lowest microhardness was observed when ERCuSi-A filler wire was used for joining. Higher values were measured when ERCuNi-30 and ER304 filler wires were used in joining of copper to stainless steel [6].

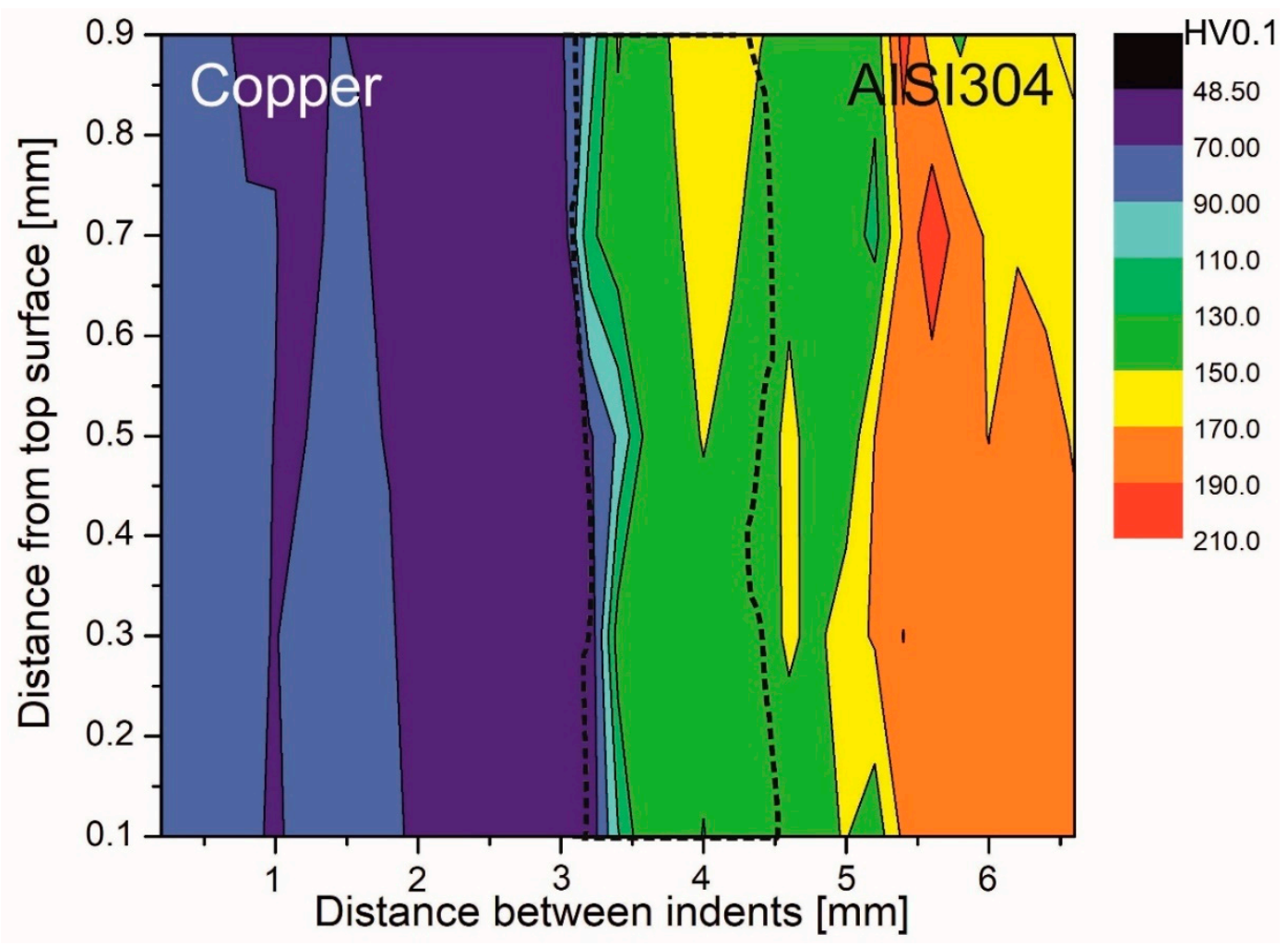

Figure 11. Microhardness map for dissimilar metals-welded joint No. 5.

\subsection{Tensile Strength Results}

Values of tensile strengths of welded joints for each sample are shown in Table 8. Samples with offset to the AISI 304 steel side reached lower values than welds produced with beam offset to copper side. Samples No. 2 and 6 possessed the lowest values of tensile strength, 66 and $70 \mathrm{MPa}$ (Figure 12). This is due to the lack of fusion caused by high offset to the AISI 304 steel side. In this case, when the lower laser power of $1.3 \mathrm{~kW}$ was used, a slightly higher tensile strength was attained.

Table 8. Measured tensile strength for dissimilar metals-welded joints.

\begin{tabular}{cc}
\hline Welded Joint No. & Tensile Strength [MPa] \\
\hline 1 & 162 \\
2 & 70 \\
3 & 166 \\
4 & 261 \\
5 & 236 \\
6 & 66 \\
7 & 256 \\
8 & 254 \\
\hline
\end{tabular}




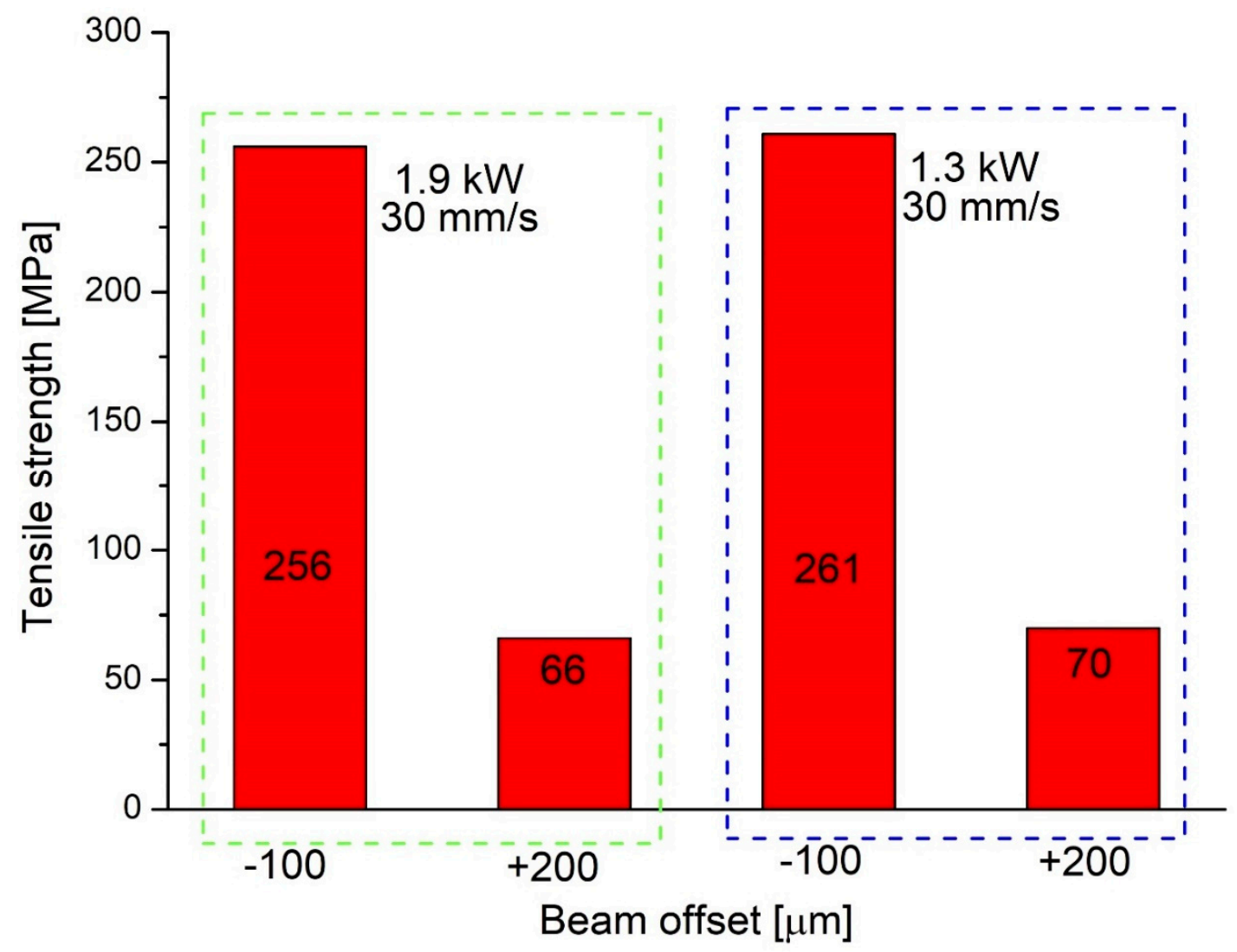

Figure 12. Influence of beam offset and laser power on weld strength.

When the lower welding speed of $20 \mathrm{~mm} / \mathrm{s}$ was used, as in the case of welded joints No. 1 and 3, higher values of tensile strengths were achieved, i.e., 162 and $166 \mathrm{MPa}$, respectively. All welded samples with offset to the AISI 304 side fractured in the welded joint or AISI 304-weld metal interface.

Tensile strength for all samples welded with offset to the copper side reached higher values, up to $261 \mathrm{MPa}$. When comparing welded joints No. 4 and 7, beam offsets to copper side were used, but with different laser powers. The maximum strength was reached when a laser power of $1.3 \mathrm{~kW}$ was used (261 MPa). Increase in laser power to $1.9 \mathrm{~kW}$ (other parameters were kept constant) resulted in a slight decrease in weld strength to $256 \mathrm{MPa}$. Fractures in these welded joints appeared on the HAZ of copper side. A similar phenomenon was observed by Lampa et al. [33] during the welding of 1-mm-thick copper plate (SS 5015) to 1.5-mm-thick austenitic stainless-steel plate (ASTM 304 L) by $\mathrm{CO}_{2}$ laser in different shielding gases. Regardless of the used shielding gas, all welds failed in the copper side and none of the weld strengths was lower compared to the copper alloy [33].

The dependence of different beam offset on tensile strength confirmed that offset had great influence on tensile strength. With offset to the copper side, values can be up to 3.7 times higher in comparison to offset to AISI 304 side. Yao et al. [34] used continuous $\mathrm{CO}_{2}$ laser for welding copper to low-carbon steel and reached only values up to $233 \mathrm{MPa}$ [34].

Zhang et al. [17] evaluated also the influence of beam offset on tensile strength of electron beam welds between QCr0.8 copper alloy and AISI 304 steel. They used copper filler material with Sn as the main alloying element $(0.62 \%)$. The authors observed that tensile strength dropped with the rise in the beam offset.

Stress-strain curve for samples No. 1 and 5 is documented in Figure 13. There was a large difference in achieved values. Tensile strength of weld No. 1 was $162 \mathrm{MPa}$, and that of sample No. 5 reached $236 \mathrm{MPa}$. With the only difference being beam offset, results suggest that offset had large influence on tensile strength of produced welds. Singh et al. [7] observed that the tensile strength reached the value of $194 \mathrm{MPa}$ when GTAW process with offsetting $1.25 \mathrm{~mm}$ to copper side was used. 


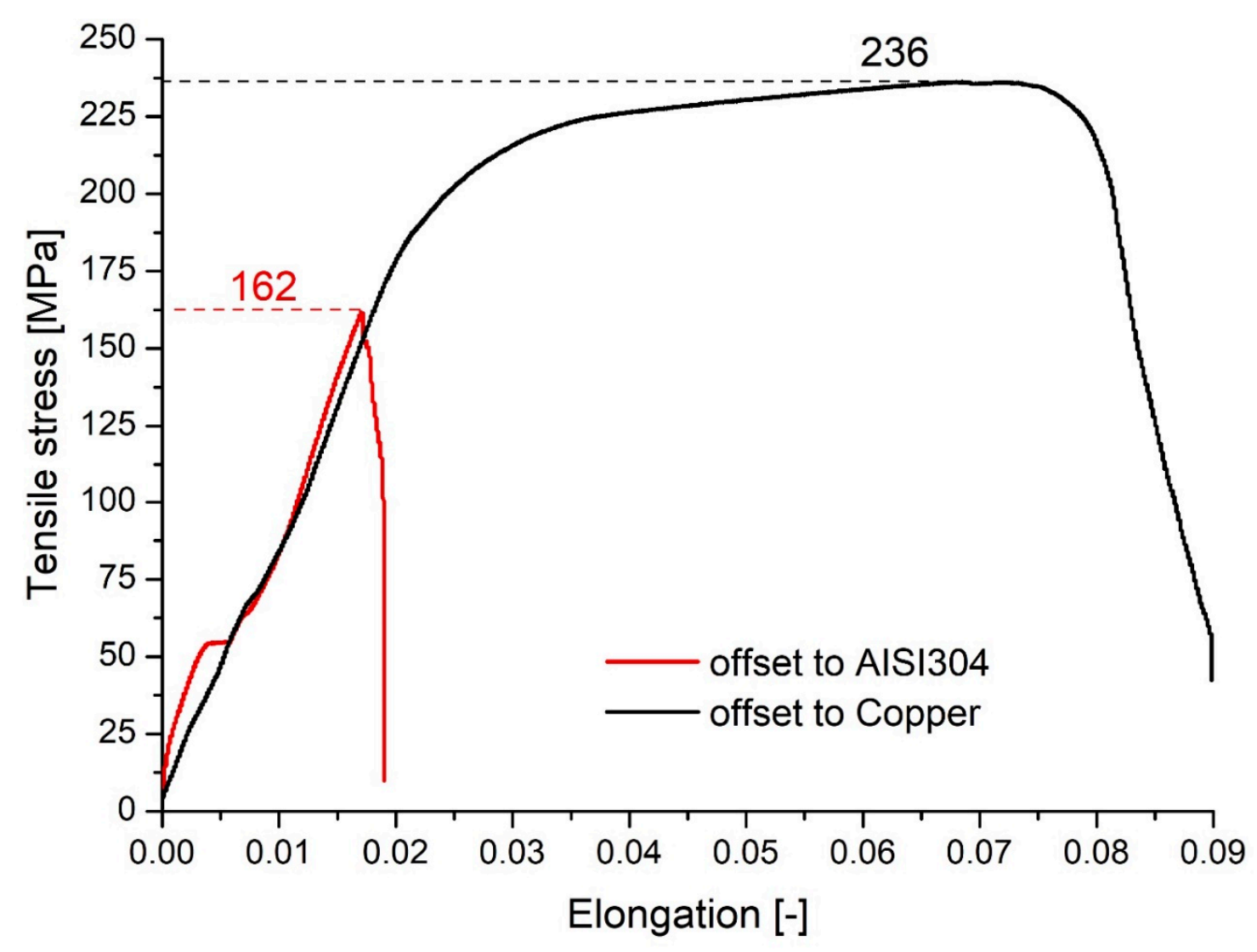

Figure 13. Stress-strain curves for welded joints Nos. 1 and 5.

A more pronounced difference was in the case of welds Nos. 6 and 7. Both samples were welded with laser power of $1.9 \mathrm{~kW}$ and a higher welding speed of $30 \mathrm{~mm} / \mathrm{s}$. In this case, a lower heat input was used for fabrication of welded joints. The only difference was the beam offset to the opposite sides. Beam offset of $200 \mu \mathrm{m}$ to the AISI 304 side was used for sample No. 6 and $100 \mu \mathrm{m}$ to the C12200 side for sample No. 7. In this case, the difference in values was even more significant. For sample No. 6 tensile strength was only $66 \mathrm{MPa}$, and for sample No. 7 it was $256 \mathrm{MPa}$. The strength value was more than $3.8 \times$ higher than that for sample No. 6 . Such significant difference confirmed that offset to the C12200 side had important influence on tensile strength of the welds.

\subsection{Fracture Surfaces}

Fracture surfaces after tensile testing of weld No. 5 are given in Figure 14a-d. The fracture was observed at the HAZ of copper sheet. The surface is characterized by transgranular fracture. Secondary cracking was not documented. The characteristic of fracture exhibited typical features of ductile type. Dimples of various sizes were observed at the surfaces. In local sites, very fine dimples were observed. Furthermore, zones with coarse dimples were observed. The presence of larger dimples resulted from the coarser structure of HAZ, where the peak temperatures were developed. Ramachandran et al. [11] observed at copper HAZ of mainly coarse dimples after impact testing. The authors found that larger dimples resulted in a drop of fracture toughness of copper HAZ [11]. Zhao et al. [35] studied beam offset in welding titanium TA2 to 301L stainless steel with and without copper interlayer. Analysis of the fracture surface revealed the presence of copper-rich and $\mathrm{Cu}$-Ti compounds when $\mathrm{Cu}$ interlayer was used. The mentioned phases were the locations characterized by brittle fracture in their study [35]. 

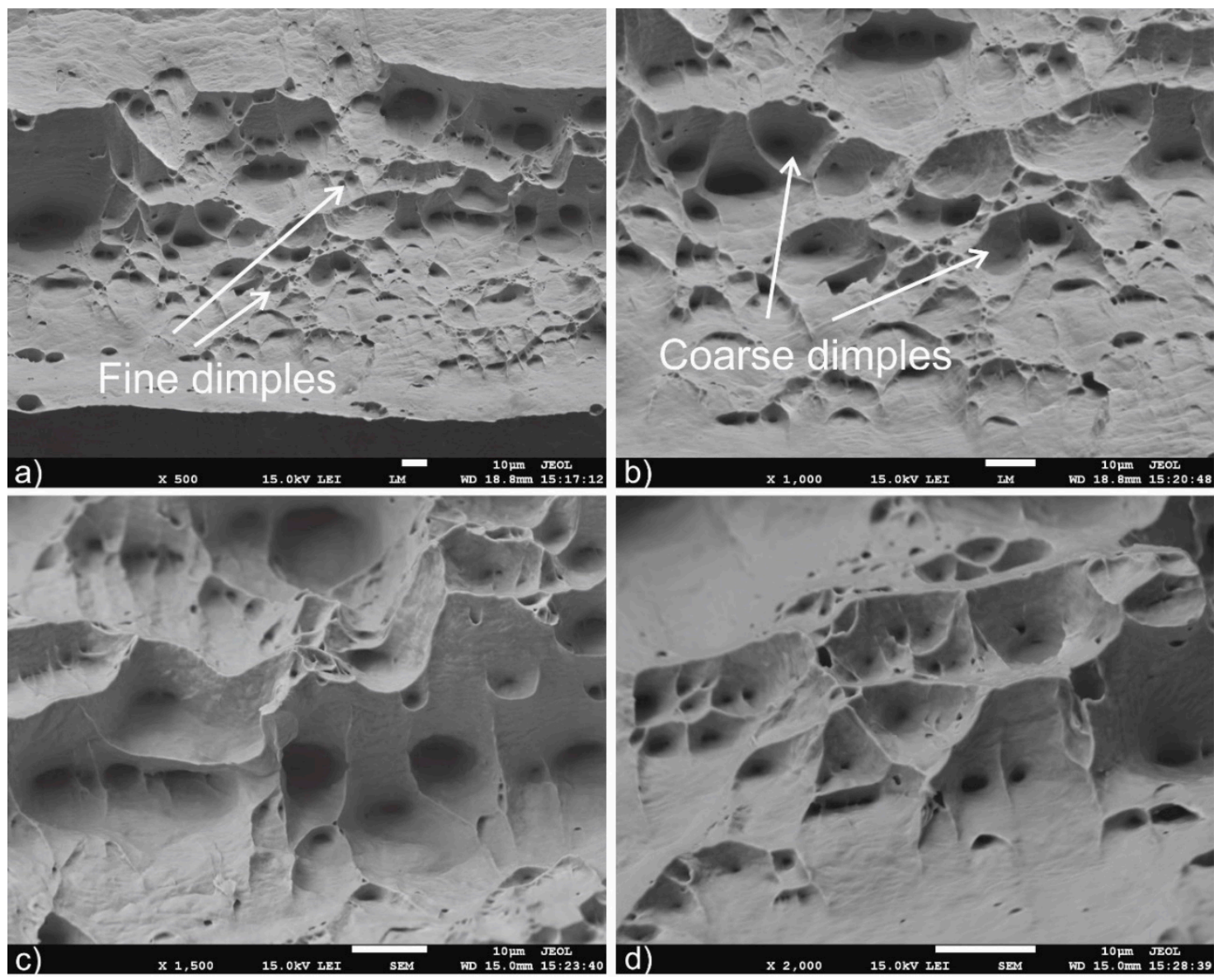

Figure 14. Fracture surfaces after tensile testing weld No. 5. (a) fine dimples zone of fracture surface,

(b) coarse dimples, (c,d) higher magnification of zone observed in (b).

\subsection{Statistical Analysis Results}

The linear dependence of tensile strength of welded joints on welding parameters is given in Equation (1). This mathematical relationship possesses the coefficient of correlation $R^{2}=99.92 \%$, confirming the important correlation between tensile strength of welded joints and welding parameters (laser power, welding speed, and beam offset). The probability plot of tensile strength of dissimilar metals' welds proved the normal distribution (Figure 15a). Half the samples were expected to have tensile strength lower than $200 \mathrm{MPa}$. For the other half of the samples there was more than $50 \%$ probability that their tensile strengths would reach more than $200 \mathrm{MPa}$. All the measured values must lie in the marked area. That corresponded with the actual measured tensile strengths. Analysis of variance for tensile strength of welded joints' results are given in Table 9. The $p$-value $<0.05$ means significant influence on the weld strength. Beam offset exhibited the $p$-value $=0.02$, confirming its significance. Other welding parameters possessed higher $p$-values, welding speed 0.064 , and laser power 0.358 .

The influence of individual welding parameters on the tensile strength is given in Figure 15b. As it arose from the measured values, the beam offset had the highest impact on the tensile strength of welds. 

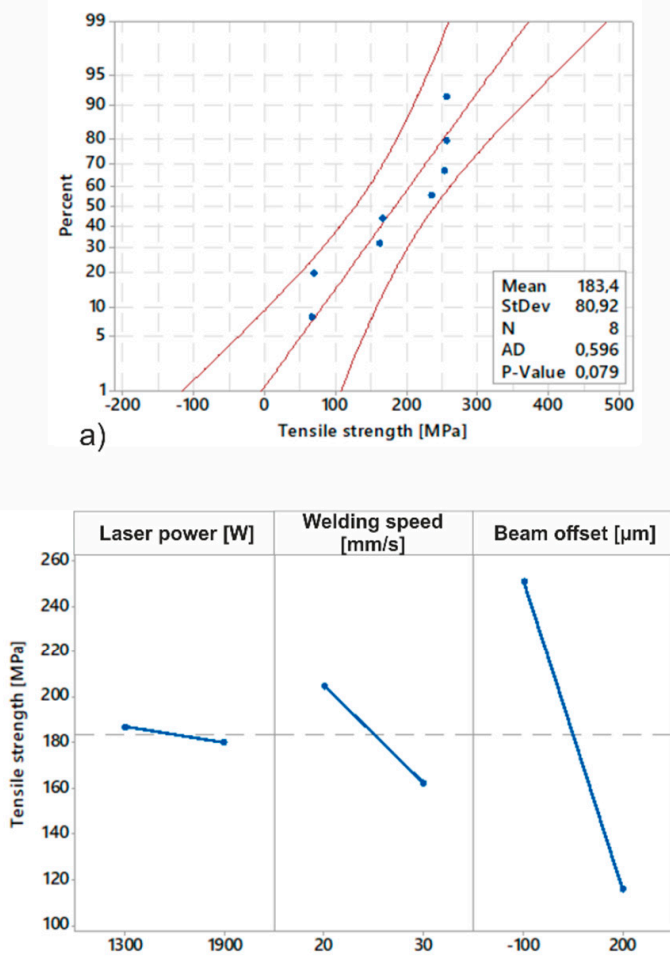

c)

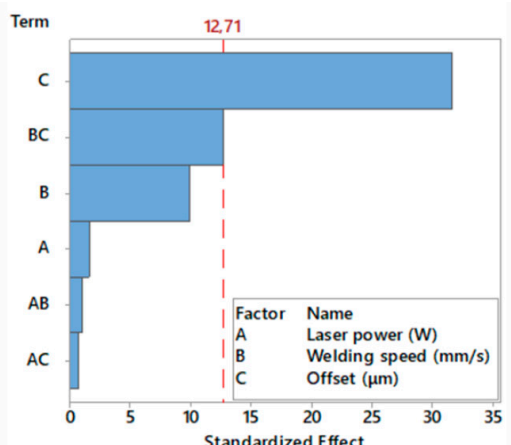

b)

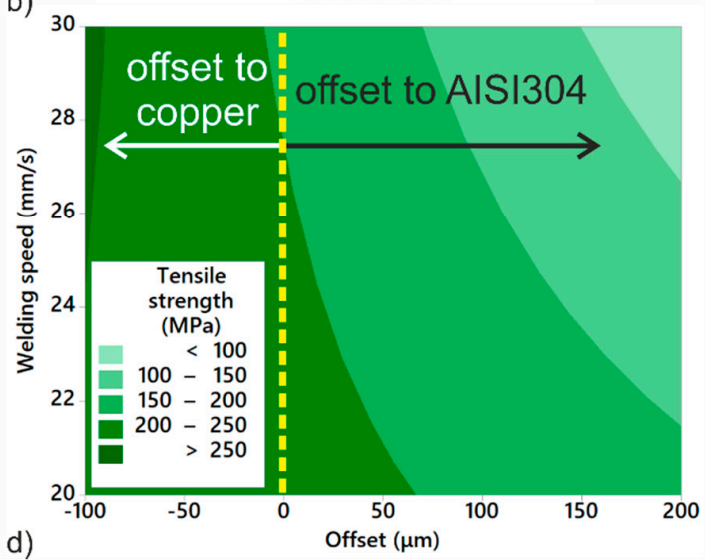

Figure 15. (a) Probability plot for tensile strength; (b) Pareto chart of the standardized effects; (c) main effects plot for tensile strength; (d) contour plot of tensile strength vs. welding speed and beam offset.

Table 9. Results of analysis of variance for tensile strength of welded joints.

\begin{tabular}{|c|c|c|c|c|c|}
\hline Source & $\mathrm{DF}^{1}$ & Adj SS ${ }^{2}$ & Adj MS $^{3}$ & $F$-Value & $p$-Value \\
\hline Model & 6 & $45,805.8$ & 7634.3 & 211.33 & 0.053 \\
\hline Linear & 3 & $39,976.4$ & $13,325.5$ & 368.87 & 0.038 \\
\hline Laser power $(\mathrm{LP})(\mathrm{W})$ & 1 & 91.1 & 91.1 & 2.52 & 0.358 \\
\hline Welding speed $(\mathrm{WS})(\mathrm{mm} / \mathrm{s})$ & 1 & 3570.1 & 3570.1 & 98.83 & 0.064 \\
\hline Offset $(\mathrm{O})(\mu \mathrm{m})$ & 1 & $36,315.1$ & $36,315.1$ & 1005.26 & 0.020 \\
\hline 2-way interactions & 3 & 5829.4 & 1943.1 & 53.79 & 0.100 \\
\hline $\mathrm{LP} * \mathrm{WS}$ & 1 & 36.1 & 36.1 & 1.00 & 0.500 \\
\hline $\mathrm{LP} * \mathrm{O}$ & 1 & 15.1 & 15.1 & 0.42 & 0.634 \\
\hline $\mathrm{WS} * \mathrm{O}$ & 1 & 5778.1 & 5778.1 & 159.95 & 0.050 \\
\hline Error & 1 & 36.1 & 36.1 & - & - \\
\hline Total & 7 & 458419 & - & - & - \\
\hline$R^{2}=99.92 \%$ & - & $R^{2}$ (adj. $)=99.45 \%$ & $R^{2}$ (pred. $)=94.96 \%$ & - & - \\
\hline
\end{tabular}

Notes: ${ }^{1}$ Degrees of freedom; ${ }^{2}$ adjusted sums of square; ${ }^{3}$ adjusted mean squares.

The main effects plot for tensile strength of welds is shown in Figure 15c. It is obvious that laser power had negligible effect on the tensile strength. As expected from previous results, the beam offset possessed the most important impact. From attaining the maximum tensile strength point of view, it was necessary to use the application of negative beam offset, lower welding speed $(20 \mathrm{~mm} / \mathrm{s})$, and lower laser power $(1.3 \mathrm{~kW})$.

Based on DoE, the dependence of tensile strength on individual welding parameters was calculated. Regression equation in uncoded units is as follows:

$$
\begin{aligned}
& \text { Tensile strength }(\mathrm{MPa})=343.8-0.0482 \times L P(\mathrm{~W})-4.70 \times W S(\mathrm{~mm} / \mathrm{s})+0.398 \times O(\mu \mathrm{m}) \\
& +0.00142 \times L P(\mathrm{~W})^{*} W S(\mathrm{~mm} / \mathrm{s})+0.000031 \times L P(\mathrm{~W}) \times O(\mu \mathrm{m})-0.03583 \times W S(\mathrm{~mm} / \mathrm{s}) \times O(\mu \mathrm{m})
\end{aligned}
$$

where $L P$ means laser power in $\mathrm{W}, W S$ is welding speed in $\mathrm{mm} / \mathrm{s}$, and $O$ is laser beam offset in $\mu \mathrm{m}$. 
As it follows from the abovementioned equation, beam offset $O$ and two-way interaction of laser power $L P$ and beam offset $O$ possessed positive influence on the overall tensile strength. Based on ANOVA results, the $p$-value for $L P \times O$ interaction was higher than 0.05 , indicating no significance of its influence on the tensile strength. In general, the main laser welding parameters are laser power, welding speed, and focus position. In our study, the focus position was set to $0 \mathrm{~mm}$, meaning that the maximum power density was on the top of the materials to be welded. Especially, it is useful in the case of welding copper where higher reflectivity of radiation can be expected. The higher heat input resulted in the formation of a larger weld pool. However, when a lower heat input was used, the differences in weld metal width were minimum, i.e., not dependent on the offset direction. Thus, controlling the weld metal composition could be done by beam offsetting. Higher amounts of elements originating from stainless steel results in intermixing and higher tensile strength of welded joints. So, when affecting the chemical composition, i.e., dilution of welded metals, it could be very beneficial to apply beam offsetting. The diameter of the focused laser beam was $200 \mu \mathrm{m}$. In the case of a higher beam offset to the AISI 304 steel, the power from the laser beam was concentrated not onto the copper part. The large part of the energy of the laser beam was utilized to melt the stainless steel. Due to the heat dissipating from the molten pool, diffusion could occur at the interface of weld metal-copper, forming a brazed interface. In this case, the reflectivity influence was negligible when the beam was offset to the stainless-steel side. Nguyen et al. [29] observed disconnections at the interface in the case of offsetting the laser beam $0.25 \mathrm{~mm}$ toward stainless steel. It is also necessary to consider different thermal conductivities of welded materials. The thermal conductivity of copper is much higher than that of stainless steel. As it follows from iron-copper binary diagram, the mutual solubility was very low. Another very important fact is that no intermetallic compounds were formed. Cheng et al. [6] observed the copper fusion boundary, the so-called unmixed zone, as a result of insufficient intermixing [6]. For the abovementioned case, also the microhardness reflected the higher values originating from steel chemical composition. Directly at the brazed interface, a darker zone was observed. The distribution of $\mathrm{Cr}, \mathrm{Ni}$, and $\mathrm{Fe}$ was like that in the bright zone.

A different situation was in the case of beam offsetting toward copper. The part of energy of the laser beam was utilized to direct melting of both materials. The brazed interface disappeared. The molten pool was formed by direct heating and melting of both materials. Meng et al. [13] observed that molten metal flowed out of the molten metal center. These actions resulted in intermixing of both molten materials, resulting in the formation of Fe-Cu-based compounds. The darker parts of the weld metal (Figure $6 \mathrm{~b}$ ) were characterized by the content of 48 at. \% of copper and 36 at. \% of iron. This was associated also with lower microhardness in comparison to when only stainless steels are joined. Bernatskyi et al. [36] carried out laser welding in various spatial positions of T-joints of austenitic stainless steel. The authors observed higher microhardness in weld metal after carrying out technological implementations [36]. The microhardness of copper-stainless steel depends on the amount of intermixed materials. When beam offset to AISI 304 was used, the microhardness was slightly higher than that in the welded joint produced with beam offset to copper. It was associated with the fact that in the case of beam offset to steel, the weld metal is characterized by an Fe-rich matrix. Contour plot of tensile strength vs. welding speed and beam offset is documented in Figure 15d. To attain welds with tensile strengths above $250 \mathrm{MPa}$, it is recommended to apply beam offset close to or the same as $100 \mu \mathrm{m}$ toward copper and use the welding speed of $25 \mathrm{~mm} / \mathrm{s}$ and above. In our case, the welded joint made with offset $100 \mu \mathrm{m}$ to the copper side and welding speed of $30 \mathrm{~mm} / \mathrm{s}$ possessed the tensile strength higher than $250 \mathrm{MPa}$. That agreed with sample No. 4 that was welded with these parameters and achieved tensile strength of $261 \mathrm{MPa}$.

\section{Conclusions}

The influence of disk laser welding parameters on the microstructure and mechanical properties of copper-AISI 304 stainless steel was investigated by means of light microscopy, electron microscopy 
including EDS analysis, microhardness measurements, and tensile testing. Based on the reached results, the following can be stated:

- DoE results showed that beam offset had the highest influence on tensile strength of dissimilar metals' welds and $p$-value for beam offset was lower than 0.05 .

- Beam offset $100 \mu \mathrm{m}$ toward copper resulted in 3.7 times higher tensile strength of welded joint in comparison to welds produced with offset to AISI 304 steel.

- When offset to copper sheet was used, higher tensile strength was attained when lower heat input was used.

- EDS analysis confirmed the heterogeneity in elemental composition across welded joint interface. The heterogeneity in elemental composition across welded joints was lower when laser beam was offset to AISI 304 steel side. On the other hand, the copper content dropped to the average composition of weld metal at the distance of about $140 \mu \mathrm{m}$ from copper-weld metal interface.

- Fracture after tensile testing was observed at the copper HAZ in the case of application of beam offset toward copper.

- Microhardness increase from copper toward weld metal was observed. The mean microhardness of austenitic stainless steel was about 215 HV0.1 and that of weld metal equaled to 179 HV0.1 when beam offset to AISI 304 steel was used. The averaged microhardness of the weld dropped to $140 \mathrm{HV} 0.1$ in the case of beam offset to copper.

Author Contributions: Conceptualization, M.S. (Miroslav Sahul) and M.S. (Martin Sahul); methodology, M.S. (Miroslav Sahul); software, E.T.; formal analysis, M.S. (Martin Sahul) and E.H.; investigation, M.S. (Miroslav Sahul), E.T., M.S. (Martin Sahul), M.P., and B.L.; data curation, M.S. (Miroslav Sahul) and E.T.; writing-original draft preparation, M.S. (Miroslav Sahul) and E.T.; writing-review and editing, M.S. (Martin Sahul); visualization, M.S. (Miroslav Sahul); supervision, M.S. (Miroslav Sahul); project administration, E.H.; funding acquisition, E.H. All authors have read and agreed to the published version of the manuscript.

Funding: The research was carried out under the support of Slovak Research and Development Agency, project No. APVV-18-0116 and Vedecká grantová agentúra VEGA grant agency of the Ministry of Education, Science, Research and Sport of the Slovak Republic, project No. 1/0091/17. This publication was supported by the Operational Programme Research and Innovation for the project: Scientific and Research Centre of Excellence SlovakION for Material and Interdisciplinary Research, code of the project ITMS2014+: 313011W085 co-financed by the European Regional Development Fund.

Conflicts of Interest: The authors declare no conflict of interest.

\section{References}

1. Landowski, M.; Świerczyńska, A.; Rogalski, G.; Fydrych, D. Autogenous fiber laser welding of 316L austenitic and 2304 lean duplex stainless steels. Materials 2020, 13, 2930. [CrossRef] [PubMed]

2. Moravec, J.; Nováková, I. The Selection of Appropriate Process Parameters of Diffusion Bonding in Heterogeneous Weld of 355J2/AISI 316L Steels. Key Eng. Mater. 2017, 737, 101-106. [CrossRef]

3. Kolařík, L.; Janovec, J.; Kolaříková, M.; Nachtnebl, P. Influence of Diffusion Welding Time on Homogenous Steel Joints. Procedia Eng. 2015, 100, 1678-1685. [CrossRef]

4. Li, J.; Cai, Y.; Yan, F.; Wang, C.; Zhu, Z.; Hu, C. Porosity and liquation cracking of dissimilar Nd:YAG laser welding of SUS304 stainless steel to T2 copper. Opt. Laser Technol. 2020, 122, 105881. [CrossRef]

5. Sahul, M.; Sahul, M.; Turňa, M.; Zacková, P. Disk Laser Welding of Copper to Stainless Steel. Adv. Mater. Res. 2014, 1077, 76-81. [CrossRef]

6. Cheng, Z.; Liu, H.; Huang, J.; Ye, Z.; Yang, J.; Chen, S. MIG-TIG double-sided arc welding of copper-stainless steel using different filler metals. J. Manuf. Process. 2020, 55, 208-219. [CrossRef]

7. Singh, G.; Saxena, R.K.; Pandey, S. An examination of mechanical properties of dissimilar AISI 304 stainless steel and copper weldment obtained using GTAW. Mater. Today Proc. 2020. [CrossRef]

8. Antony, K.; Rakeshnath, T.R. Dissimilar laser welding of commercially pure copper and stainless steel 316L. Mater. Today Proc. 2020. [CrossRef]

9. Kik, T. Heat source models in numerical simulations of laser welding. Materials 2020, 13, 2653. [CrossRef] 
10. Shiri, S.G.; Nazarzadeh, M.; Sharifitabar, M.; Afarani, M.S. Gas tungsten arc welding of CP-copper to 304 stainless steel using different filler materials. Trans. Nonferrous Met. Soc. China 2012, 22, 2937-2942. [CrossRef]

11. Ramachandran, S.; Lakshminarayanan, A.K. An insight into microstructural heterogeneities formation between weld subregions of laser welded copper to stainless steel joints. Trans. Nonferrous Met. Soc. China 2020, 30, 727-745. [CrossRef]

12. Saranarayanan, R.; Lakshminarayanan, A.K.; Venkatraman, B. A combined full-field imaging and metallography approach to assess the local properties of gas tungsten arc welded copper-stainless steel joints. Arch. Civ. Mech. Eng. 2019, 19, 251-267. [CrossRef]

13. Meng, Y.; Li, X.; Gao, M.; Zeng, X. Microstructures and mechanical properties of laser-arc hybrid welded dissimilar pure copper to stainless steel. Opt. Laser Technol. 2019, 111, 140-145. [CrossRef]

14. Chen, S.; Huang, J.; Xia, J.; Zhao, X.; Lin, S. Influence of processing parameters on the characteristics of stainless steel/copper laser welding. J. Mater. Process. Technol. 2015, 222, 43-51. [CrossRef]

15. Mannucci, A.; Tomashchuk, I.; Vignal, V.; Sallamand, P.; Duband, M. Parametric study of laser welding of copper to austenitic stainless steel. Procedia CIRP 2018, 74, 450-455. [CrossRef]

16. Kar, J.; Roy, S.K.; Roy, G.G. Effect of beam oscillation on electron beam welding of copper with AISI-304 stainless steel. J. Mater. Process. Technol. 2016, 233, 174-185. [CrossRef]

17. Zhang, B.; Zhao, J.; Li, X.; Feng, J. Electron beam welding of 304 stainless steel to QCr0.8 copper alloy with copper filler wire. Trans. Nonferrous Met. Soc. China 2014, 24, 4059-4066. [CrossRef]

18. Kuryntsev, S.V.; Morushkin, A.E.; Gilmutdinov, A.K. Fiber laser welding of austenitic steel and commercially pure copper butt joint. Opt. Lasers Eng. 2017, 90, 101-109. [CrossRef]

19. Guo, S.; Zhou, Q.; Kong, J.; Peng, Y.; Xiang, Y.; Luo, T.; Wang, K.; Zhu, J. Effect of beam offset on the characteristics of copper/304stainless steel electron beam welding. Vacuum 2016, 128, 205-212. [CrossRef]

20. Zhang, Y.; Chen, Y.; Zhou, J.; Sun, D.; Gu, X. Forming mechanism and mechanical property of pulsed laser welded Ti alloy and stainless steel joint using copper as interlayer. J. Mater. Res. Technol. 2020, 9, 1425-1433. [CrossRef]

21. Cheng, Z.; Huang, J.; Ye, Z.; Yang, J.; Chen, S. Butt brazing of titanium alloys/stainless steel plates by MIG-TIG double-sided arc welding process with copper filler metal. J. Mater. Res. Technol. 2019, 8, 1566-1570. [CrossRef]

22. Hao, X.; Dong, H.; Li, S.; Xu, X.; Li, P. Lap joining of TC4 titanium alloy to 304 stainless steel with fillet weld by GTAW using copper-based filler wire. J. Mater. Process. Technol. 2018, 257, 88-100. [CrossRef]

23. Wang, Y.; Li, X.; Wang, X.; Yan, H. Fabrication of a thick copper-stainless steel clad plate for nuclear fusion equipment by explosive welding. Fusion Eng. Des. 2018, 137, 91-96. [CrossRef]

24. Bina, M.H.; Dehghani, F.; Salimi, M. Effect of heat treatment on bonding interface in explosive welded copper/stainless steel. Mater. Des. 2013, 45, 504-509. [CrossRef]

25. Mashinini, P.M.; Hattingh, D.G. Influence of laser heat input on weld zone width and fatigue performance of Ti-6Al-4V sheet. Mater. Sci. Eng. B 2020, 262, 114699. [CrossRef]

26. Huang, R.; Tan, C.; Sun, Y.; Gong, X.; Wu, L.; Chen, B.; Zhao, H.; Song, X. Influence of processing window on laser welding-brazing of $\mathrm{Al}$ to press-hardened 22MnB5 steel. Opt. Laser Technol. 2021, 133, 106566. [CrossRef]

27. Chen, X.; Lei, Z.; Chen, Y.; Han, Y.; Jiang, M.; Tian, Z.; Bi, J.; Lin, S. Microstructure and tensile properties of Ti/Al dissimilar joint by laser welding-brazing at subatmospheric pressure. J. Manuf. Process. 2020, 56, $19-27$. [CrossRef]

28. Yang, J.; Chen, J.; Zhao, W.; Zhang, P.; Yu, Z.; Li, Y.; Zeng, Z.; Zhou, N. Diode laserwelding/brazing of aluminum alloy to steel using a nickel coating. Appl. Sci. 2018, 8, 922. [CrossRef]

29. Nguyen, Q.; Azadkhou, A.; Akbari, M.; Panjehpour, A.; Karimipour, A. Experimental investigation of temperature field and fusion zone microstructure in dissimilar pulsed laser welding of austenitic stainless steel and copper. J. Manuf. Process. 2020, 56, 206-215. [CrossRef]

30. Chen, S.; Huang, J.; Xia, J.; Zhang, H.; Zhao, X. Microstructural Characteristics of a Stainless Steel/Copper Dissimilar Joint Made by Laser Welding. Metall. Mater. Trans. A 2013, 44, 3690-3696. [CrossRef]

31. Weigl, M.; Schmidt, M. Influence of the feed rate and the lateral beam displacement on the joining quality of laser-welded copper-stainless steel connections. Phys. Procedia 2010, 5, 53-59. [CrossRef]

32. Turna, M.; Sahul, M.; Ondruska, J.; Lokaj, J. Electron beam welding of copper to stainless steel. Ann. DAAAM Proc. Int. DAAAM Symp. 2011, 22, 833-834. 
33. Lampa, C.; Powell, J.; Magnusson, C. Laser welding of copper to stainless steel. Laser Inst. Am. Proc. 1997, 83, G171-G180. [CrossRef]

34. Yao, C.; Xu, B.; Zhang, X.; Huang, J.; Fu, J.; Wu, Y. Interface microstructure and mechanical properties of laser welding copper-steel dissimilar joint. Opt. Lasers Eng. 2009, 47, 807-814. [CrossRef]

35. Zhao, X.; Shi, Z.; Deng, C.; Liu, Y.; Li, X. The effect of laser offset welding on microstructure and mechanical properties of 301L to TA2 with and without $\mathrm{Cu}$ intermediate layer. Metals 2020, 10, 1138. [CrossRef]

36. Bernatskyi, A.V.; Berdnikova, O.M.; Klochkov, I.M.; Sydorets, V.M.; Chinakhov, D.A. Laser Welding in Different Spatial Positions of T-joints of Austenitic Steel. IOP Conf. Ser. Mater. Sci. Eng. 2019, 582, 012048. [CrossRef]

(C) 2020 by the authors. Licensee MDPI, Basel, Switzerland. This article is an open access article distributed under the terms and conditions of the Creative Commons Attribution (CC BY) license (http://creativecommons.org/licenses/by/4.0/). 